\title{
Effect of $n$-3 (Omega-3) Polyunsaturated Fatty Acid Supplementation on Metabolic and Inflammatory Biomarkers and Body Weight in Patients with Type 2 Diabetes Mellitus: A Systematic Review and Meta-Analysis of RCTs
}

\author{
Leila Khalili $^{1, *(\mathbb{D}}$, Roxana Valdes-Ramos ${ }^{2}\left(\mathbb{D}\right.$ and Laurence S. Harbige ${ }^{3, *}$ \\ 1 Department of Community Nutrition, Faculty of Nutrition and Food Sciences, Tabriz University of Medical \\ Sciences, Tabriz 51368, Iran \\ 2 Lider del Cuerpo Academico de Nutricion y Salud, Facultad de Medicina, Universidad Autonoma del Estado \\ de Mexico, Paseo Tollocan, esq. Jesus Carranza, Col. Moderna de la Cruz, Toluca 52180, Mexico; \\ rvaldesr@uaemex.mx \\ 3 Lipidomics and Nutrition Research Centre, London Metropolitan University, 166-220 Holloway Road, \\ London N7 8DB, UK \\ * Correspondence: leylakhalili1990@gmail.com (L.K.); 1.harbige@londonmet.ac.uk (L.S.H.)
}

\section{check for} updates

Citation: Khalili, L.; Valdes-Ramos, R.; Harbige, L.S. Effect of $n-3$ (Omega-3) Polyunsaturated Fatty Acid Supplementation on Metabolic and Inflammatory Biomarkers and Body Weight in Patients with Type 2 Diabetes Mellitus: A Systematic Review and Meta-Analysis of RCTs. Metabolites 2021, 11, 742. https:// doi.org/10.3390/metabo11110742

Academic Editor: Jan W. Eriksson

Received: 22 August 2021

Accepted: 23 October 2021

Published: 28 October 2021

Publisher's Note: MDPI stays neutral with regard to jurisdictional claims in published maps and institutional affiliations.

Copyright: (c) 2021 by the authors. Licensee MDPI, Basel, Switzerland. This article is an open access article distributed under the terms and conditions of the Creative Commons Attribution (CC BY) license (https:// creativecommons.org/licenses/by/ $4.0 /)$.
Abstract: Beneficial effects of $n-3$ fatty acids on metabolic biomarkers in patients with type 2 diabetes (T2DM) has been reported. The objectives of this current research were to investigate the effects of $n-3$ supplementation on metabolic factors, weight, and body mass index (BMI) in patients with type 2 diabetes mellitus (T2DM), using a meta-analysis of randomized, controlled trials (RCTs). Online databases PubMed, Embase, Web of Science, and Science Direct were searched until 2021 to identify eligible articles. Thirty trials were included. The results showed that $n-3$ consumption can significantly reduce glycemic factors including fasting blood sugar (FBS) $(-0.36$ ( -0.71 to -0.01$)$ ), glycated hemoglobulin (HbA1c) $(-0.74(-1.13$ to -0.35$))$, and homeostatic model assessment of insulin resistance (HOMA.IR) $(-0.58(-1.13$ to -0.03$))$. Furthermore, significant improvement in lipid profile including triglycerides (TG) $(-0.27(-0.37$ to -0.18$))$, total cholesterol $(-0.60(-0.88$ to $-0.32)$ ), low density lipoprotein (LDL) ( -0.54 ( -0.85 to -0.23$)$ ), and high-density lipoprotein (HDL) (0.60 (0.23 to 0.96)) levels were found in the present meta-analysis. The reduction in the inflammatory marker's tumor necrosis factor-alpha (TNF- $\alpha)(-0.13(-0.75$ to 0.48$))$ and c-reactive protein $(\mathrm{CRP})$ $(-0.72(-1.70$ to 0.27$))$, as well as weight $(-0.09(-0.24$ to 0.07$))$ and BMI $(-0.13(-0.29$ to 0.02$))$ were not statistically significant. Furthermore, the findings revealed that the optimal dose and duration of $n-3$ consumption for patients with T2DM is $1000-2000 \mathrm{mg} / \mathrm{d}$ for more than 8 weeks. The present meta-analysis and review reveals that $n-3$ supplementation can improve glycemic factors and lipid profile in patients with T2DM. Furthermore, $n-3$ supplementation may provide beneficial effects on inflammatory markers and body weight if used at the appropriate dose and duration.

Keywords: meta-analysis; $n$-3; polyunsaturated fatty acids PUFA; T2DM; diabetes; randomized controlled trials RCTs; glycemic control; metabolic and inflammatory biomarkers; weight; BMI

\section{Introduction}

Type 2 diabetes (T2DM) is a metabolic disorder characterized by hyperglycemia in the context of insulin resistance and $\beta$-cell dysfunction. Its prevalence is increasing at an alarming rate worldwide [1,2]. Epidemiological and clinical trials have demonstrated that lifestyle, in particular daily diet, is of importance in the development and treatment of T2DM [3]. 
It has been reported that high fish and seafood consumption can significantly reduce the incidence of T2DM [4]. Bang et al. attributed such benefits of fish consumption to its main components, $n-3$ fatty acids (in particular eicosapentaenoic acid (C20: $5 n-3$, EPA) and docosahexaenoic acid (C22: $6 n-3$, DHA)) a family of homologue polyunsaturated fatty acids (PUFAs) [5].

Recent data supports the beneficial effects of $n-3$ PUFAs intake on metabolic profiles in patients with T2DM and obesity [6], and gestational diabetes (GDM) [7]. Several studies have reported that circulating levels of $n-3$ fatty acid were negatively associated with the risk of T2DM [8,9]. Moreover, some studies have demonstrated that $n-3$ fatty acids administration improve insulin sensitivity in overweight women with an inflammatory phenotype [10], whereas others observed that $n-3$ fatty acids in healthy people have no insulin-sensitizing effects [11]. Interestingly, favorable effects of $n-3$ fatty acids on inflammation and oxidative stress have been reported in patients with a high inflammatory status including pregnant women with GDM [12] and cancer-related cachexia [13]. These discrepancies may be explained by the different population studies, the origin of $n-3$ fatty acids, dosage, and length of treatment. Considering that the pathogenesis of T2DM may be linked to impaired metabolic profiles, inflammation and oxidative stress and as there is evidence that $n-3$ fatty acids may have anti-inflammatory effects and reduce oxidative stress [12], several trials have been conducted evaluating the beneficial effect of $n-3$ polyunsaturated fatty acids (PUFA) consumption on metabolic parameters in patients with T2DM.

The purpose of the present study was to perform a systematic review and metaanalysis of randomized controlled trials (RCTs) on the effects of $n-3$ PUFAs, both the parent alpha-linolenic acid (ALA, C18: $3 n-3$ ) and the longer chain n-3 PUFA EPA and DHA, on metabolic biomarkers including glycemic profile, lipid profiles, and inflammatory parameters and body weight and body mass index (BMI) in patients with T2DM.

\section{Results}

The literature search yielded 4105 citations. We retrieved 94 articles, of which 30 met eligibility criteria. A flow chart on article selection for the meta-analysis is shown in Figure 1.

\subsection{Characteristics of Included Studies}

Table 1 contains specific information on intervention dosages and duration of treatment, and measurement parameters in studies. Thirty randomized clinical trials were included in the final meta-analysis. Twenty-four studies reported changes in glycemic factors, 20 studies reported changes in lipid profile, 13 studies reported changes in body weight, and 6 studies reported changes in inflammatory markers (Table 1). The subjects of all studies consumed $n-3$ as oral supplementation. 
Table 1. Characteristics of included studies.

\begin{tabular}{|c|c|c|c|c|c|c|c|c|c|c|c|c|c|c|c|c|}
\hline \multirow{3}{*}{$\mathbf{N}$} & & & \multirow{3}{*}{ Supplement Type } & \multirow{3}{*}{$\begin{array}{c}\text { Duration } \\
\text { (Weeks) }\end{array}$} & \multirow{3}{*}{$\begin{array}{c}\text { Dose } \\
\text { (mg/d) }\end{array}$} & \multicolumn{11}{|c|}{ Analysis } \\
\hline & \multirow{2}{*}{\multicolumn{2}{|c|}{ ID }} & & & & \multicolumn{3}{|c|}{ Glycemic Factors } & \multicolumn{4}{|c|}{ Lipid Profile } & \multicolumn{2}{|c|}{ Inflammatory Markers } & \multirow{2}{*}{ Weight } & \multirow{2}{*}{ BM } \\
\hline & & & & & & FBS & HbA1c & HOMA.IR & TG & Chol & LDL & HDL & TNF- $\alpha$ & CRP & & \\
\hline 1 & \multicolumn{2}{|c|}{ Hajianfar, [14] } & $n-3$ capsules & 8 & - & & & & & & & & & & $\checkmark$ & $\checkmark$ \\
\hline 2 & \multicolumn{2}{|c|}{ Golpour, [15] } & $n-3$ capsules & 10 & 2700 & $\checkmark$ & $\checkmark$ & $\checkmark$ & & & & & & & $\checkmark$ & $\checkmark$ \\
\hline 3 & \multicolumn{2}{|c|}{ Dasarathy, [16] } & EPA/DHA supplement & 48 & 3600 & $\checkmark$ & $\checkmark$ & $\checkmark$ & & $\checkmark$ & & $\checkmark$ & & & $\checkmark$ & $\checkmark$ \\
\hline 4 & \multicolumn{2}{|c|}{ Mirhashemi, [17] } & flaxseed oil & 12 & 1000 & & & & & & & & $\checkmark$ & & $\checkmark$ & \\
\hline 5 & \multicolumn{2}{|c|}{ Orang, [18] } & $n$-3 capsules & 12 & 2000 & $\checkmark$ & $\checkmark$ & $\checkmark$ & & & & & $\checkmark$ & $\checkmark$ & $\checkmark$ & $\checkmark$ \\
\hline 7 & \multicolumn{2}{|c|}{ Javid, [20] } & $n-3$ capsules & 8 & 2000 & $\checkmark$ & $\checkmark$ & & $\checkmark$ & $\checkmark$ & $\checkmark$ & $\checkmark$ & & & $\checkmark$ & $\checkmark$ \\
\hline 8 & \multicolumn{2}{|c|}{ Soleimani, [21] } & flaxseed oil & 12 & 1000 & $\checkmark$ & $\checkmark$ & $\checkmark$ & $\checkmark$ & $\checkmark$ & $\checkmark$ & $\checkmark$ & & $\checkmark$ & $\checkmark$ & $\checkmark$ \\
\hline 9 & \multicolumn{2}{|c|}{ Soleimani, [22] } & flaxseed oil & 12 & 1000 & $\checkmark$ & & & $\checkmark$ & $\checkmark$ & $\checkmark$ & $\checkmark$ & & $\checkmark$ & & \\
\hline 10 & \multicolumn{2}{|c|}{ Veleba, [23] } & EPA + DHA concentrate & 24 & 5000 & $\checkmark$ & $\checkmark$ & & $\checkmark$ & $\checkmark$ & $\checkmark$ & $\checkmark$ & & & $\checkmark$ & $\checkmark$ \\
\hline 11 & \multicolumn{2}{|c|}{ Ansari, [24] } & $n-3$ capsules & 10 & 3750 & $\checkmark$ & $\checkmark$ & $\checkmark$ & & & & & & & $\checkmark$ & $\checkmark$ \\
\hline 12 & \multicolumn{2}{|c|}{ Jacobo-Cejudo, [25] } & fish-oil & 24 & 520 & $\checkmark$ & $\checkmark$ & $\checkmark$ & $\checkmark$ & $\checkmark$ & $\checkmark$ & $\checkmark$ & & & $\checkmark$ & $\checkmark$ \\
\hline 13 & \multicolumn{2}{|c|}{ Kabir, [26] } & fish-oil & 8 & 3000 & $\checkmark$ & $\checkmark$ & & $\checkmark$ & & $\checkmark$ & $\checkmark$ & $\checkmark$ & & $\checkmark$ & \\
\hline 14 & \multicolumn{2}{|c|}{ Hosseinzadeh, [27] } & $n-3$ capsules & 8 & 2000 & & & & & & & & & & $\checkmark$ & $\checkmark$ \\
\hline & & $\mathrm{A}$ & & 4 & & $\checkmark$ & $\checkmark$ & $\checkmark$ & $\checkmark$ & $\checkmark$ & $\checkmark$ & $\checkmark$ & & & & \\
\hline 16 & Hua, [29] & B & Fish oil & 8 & 2000 & $\checkmark$ & $\checkmark$ & $\checkmark$ & $\checkmark$ & $\checkmark$ & $\checkmark$ & $\checkmark$ & & & & \\
\hline & & $\mathrm{C}$ & & 12 & & $\checkmark$ & $\checkmark$ & $\checkmark$ & $\checkmark$ & $\checkmark$ & $\checkmark$ & $\checkmark$ & & & & \\
\hline & & $\mathrm{A}$ & & 6 & 1000 & $\checkmark$ & & & $\checkmark$ & $\checkmark$ & & $\checkmark$ & & & & \\
\hline 17 & 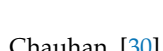 & B & $n-3$ capsule & 12 & 2000 & $\checkmark$ & $\checkmark$ & & $\checkmark$ & $\checkmark$ & $\checkmark$ & $\checkmark$ & & & & \\
\hline 17 & Chauhan, [30] & $\mathrm{C}$ & $n-3$ capsule & 6 & 1000 & $\checkmark$ & & & $\checkmark$ & $\checkmark$ & & $\checkmark$ & & & & \\
\hline & & $\mathrm{D}$ & & 12 & 2000 & $\checkmark$ & $\checkmark$ & & $\checkmark$ & $\checkmark$ & $\checkmark$ & $\checkmark$ & & & & \\
\hline 18 & Shidfa & [31] & Purified $n-3$ & 10 & 2000 & $\checkmark$ & $\checkmark$ & & $\checkmark$ & $\checkmark$ & $\checkmark$ & $\checkmark$ & & & & \\
\hline 19 & Udup & [32] & $n-3$ soft gels & 13 & 300 & $\checkmark$ & $\checkmark$ & & & & & & & & & \\
\hline & & $\mathrm{A}$ & & 4 & & $\checkmark$ & $\checkmark$ & $\checkmark$ & $\checkmark$ & $\checkmark$ & $\checkmark$ & & & & & \\
\hline 20 & Liu, [33] & B & fish oil & 8 & 3650 & $\checkmark$ & $\checkmark$ & $\checkmark$ & $\checkmark$ & $\checkmark$ & $\checkmark$ & $\checkmark$ & & & & \\
\hline & & C & & 12 & & $\checkmark$ & $\checkmark$ & $\checkmark$ & $\checkmark$ & $\checkmark$ & $\checkmark$ & $\checkmark$ & & & & \\
\hline
\end{tabular}


Table 1. Cont.

\begin{tabular}{|c|c|c|c|c|c|c|c|c|c|c|c|c|c|c|c|c|}
\hline \multirow{3}{*}{$\mathbf{N}$} & & & \multirow{3}{*}{ Supplement Type } & \multirow{3}{*}{$\begin{array}{l}\text { Duration } \\
\text { (Weeks) }\end{array}$} & \multirow{3}{*}{$\begin{array}{c}\text { Dose } \\
\text { (mg/d) }\end{array}$} & \multicolumn{11}{|c|}{ Analysis } \\
\hline & \multirow{2}{*}{\multicolumn{2}{|c|}{ ID }} & & & & \multicolumn{3}{|c|}{ Glycemic Factors } & \multicolumn{4}{|c|}{ Lipid Profile } & \multicolumn{2}{|c|}{ Inflammatory Markers } & \multirow{2}{*}{ Weight } & \multirow{2}{*}{ BMI } \\
\hline & & & & & & FBS & HbA1c & HOMA.IR & TG & Chol & LDL & HDL & TNF- $\alpha$ & CRP & & \\
\hline 21 & \multicolumn{2}{|c|}{ Mansoori, [34] } & fish oil & 8 & 1850 & $\checkmark$ & & $\checkmark$ & $\checkmark$ & $\checkmark$ & $\checkmark$ & $\checkmark$ & & & & \\
\hline 22 & \multicolumn{2}{|c|}{ Pooya, [35] } & $n-3$ capsules & 8 & 2714 & $\checkmark$ & $\checkmark$ & & & $\checkmark$ & $\checkmark$ & & & $\checkmark$ & & \\
\hline 23 & \multicolumn{2}{|c|}{ Fayh, [36] } & $n-3$ capsules & 8 & 300 & $\checkmark$ & $\checkmark$ & & $\checkmark$ & $\checkmark$ & $\checkmark$ & $\checkmark$ & & & & \\
\hline 24 & \multicolumn{2}{|c|}{ Poursoleiman, [37] } & $n-3$ soft gels & 6 & 2000 & $\checkmark$ & & & $\checkmark$ & $\checkmark$ & $\checkmark$ & $\checkmark$ & & & & \\
\hline 25 & Wang, [38] & $\mathrm{A}$ & fish oil & 12 & 4000 & $\checkmark$ & $\checkmark$ & $\checkmark$ & $\checkmark$ & $\checkmark$ & $\checkmark$ & $\checkmark$ & & & & \\
\hline 26 & \multicolumn{2}{|c|}{ Sarbolouki, [39] } & purified EPA & 12 & 2000 & $\checkmark$ & $\checkmark$ & $\checkmark$ & & & & & & & & \\
\hline \multirow{2}{*}{27} & \multirow{2}{*}{ Woodman, [40] } & $\mathrm{A}$ & purified EPA & 6 & 4000 & $\checkmark$ & $\checkmark$ & & $\checkmark$ & $\checkmark$ & $\checkmark$ & $\checkmark$ & & & & \\
\hline & & $\mathrm{B}$ & purified DHA & 6 & 4000 & $\checkmark$ & $\checkmark$ & & $\checkmark$ & $\checkmark$ & $\checkmark$ & $\checkmark$ & & & & \\
\hline \multirow{2}{*}{28} & \multirow{2}{*}{ Zheng, [22] } & A & \multirow{2}{*}{ fish oil } & 12 & \multirow{2}{*}{2000} & $\checkmark$ & $\checkmark$ & $\checkmark$ & & $\checkmark$ & $\checkmark$ & $\checkmark$ & & & & \\
\hline & & B & & 26 & & $\checkmark$ & $\checkmark$ & $\checkmark$ & & $\checkmark$ & $\checkmark$ & $\checkmark$ & & & & \\
\hline 29 & Holmar & & $n$-3 capsules & 28 & 2000 & & $\checkmark$ & & & $\checkmark$ & $\checkmark$ & $\checkmark$ & & & & \\
\hline 30 & Siniarsk & & juice box & 12 & 2000 & & & & $\checkmark$ & $\checkmark$ & $\checkmark$ & $\checkmark$ & & & & \\
\hline
\end{tabular}




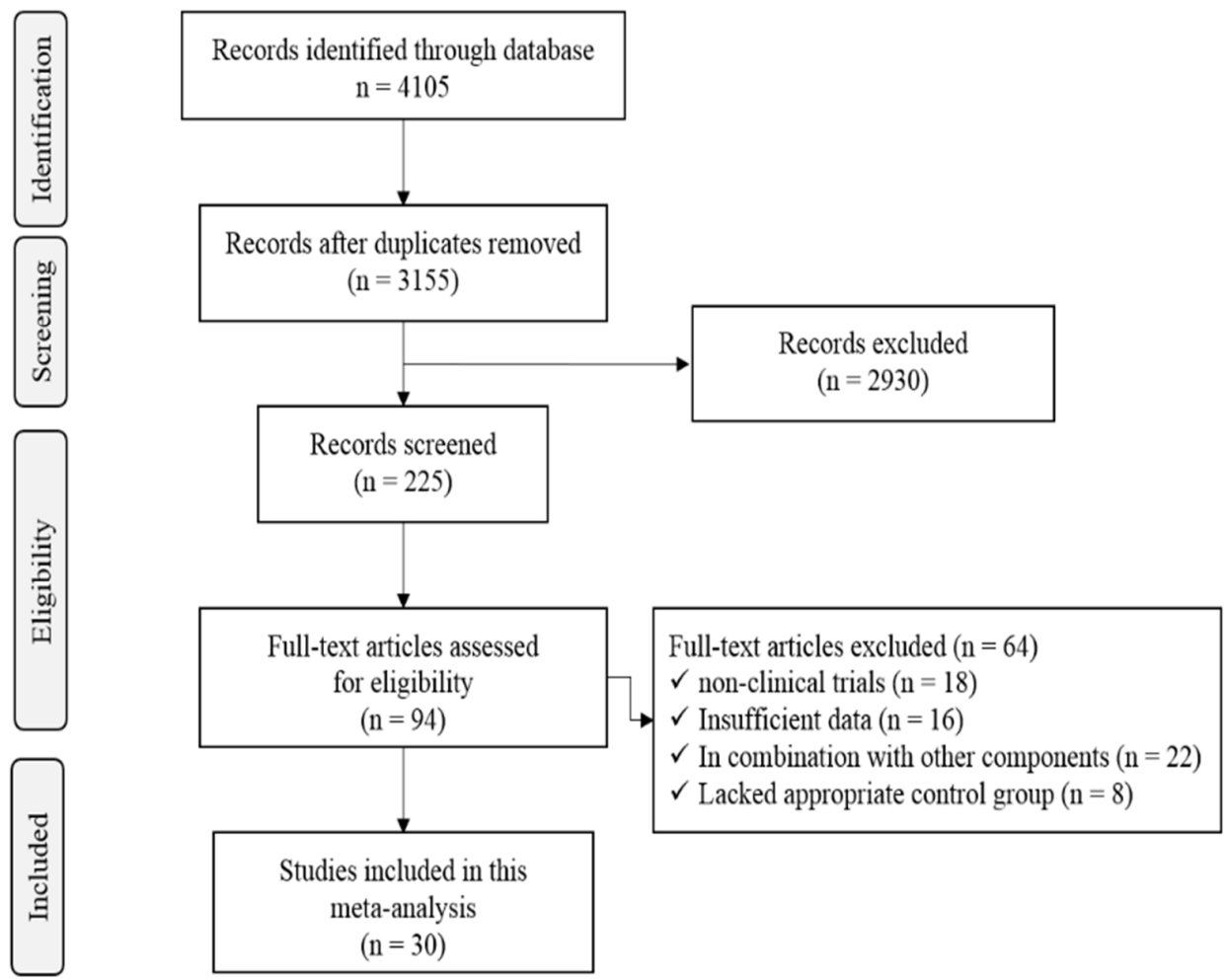

Figure 1. PRISMA flow chart of study selection process.

2.2. Meta-Analysis Results

2.2.1. Glycemic Factors

FBS

The common SMD from 24 studies was -0.36 (95\% CI: -0.71 to $-0.01, p=0.047)$ based on a random effect model, with significant heterogeneity between studies $\left(\mathrm{I}^{2}=92.9 \%\right.$, $p=0.00$ ) (Figure 2A). Further investigation detected 7 outliers with large effect sizes (Liu, 2018 A, SMD = -7.17; Liu, 2018 B, SMD = -8.57; Liu, 2018 C, SMD = -10.73; Fayh, 2018, $\mathrm{SMD}=$ 2.24; Veleba, 2015, SMD = 2.84; Woodman, $2002 \mathrm{~A}, \mathrm{SMD}=9.81$; Woodman, $2002 \mathrm{~B}$, $\mathrm{SMD}=9.07)$, so we removed them from further analyses in this outcome. Removing these studies resulted in a reduction in effect size (SMD $=-0.28,95 \% \mathrm{CI}:-0.46$ to -0.10$)$, but heterogeneity still remained significant although considerable reduction in heterogeneity was observed $\left(\mathrm{I}^{2}=72.2 \%, p=0.00\right)$. According to the shape of the funnel plot, we considered that there was no obvious publication bias among the included studies (Figure 2B).

$\mathrm{HbA1c}$

The common SMD from 21 studies was -0.74 (95\% CI: -1.13 to $-0.35, p=0.00)$ based on a random effect model, with significant heterogeneity between studies $\left(\mathrm{I}^{2}=94.8 \%\right.$, $p=0.00$ ) (Figure 3A). Further investigation detected 9 outliers with large effect sizes (Hua, 2019 C, SMD = -2.45; Holman, 2009, SMD = 0.5; Liu, 2018 B, SMD = -2.33; Liu, 2018 C, SMD = -6.67; Dasarathy, 2015, SMD = 0.5; Soleimani, 2017, SMD = -1.11; Veleba, 2015, SMD = 1.17; Cejudo, 2017, SMD = 2.55; Sarbolouki, 2013, SMD = -0.97), thus these were removed from the analyses in this outcome. Removing these studies resulted in a reduction in effect size (SMD $=-0.55,95 \% \mathrm{CI}:-0.90$ to -0.20$)$, but heterogeneity remained significant although considerable reduction in heterogeneity was observed $\left(\mathrm{I}^{2}=88.5 \%\right.$, $p=0.00)$. According to the shape of funnel plot, we considered that there was no obvious publication bias among the included studies (Figure 3B). 
(A)

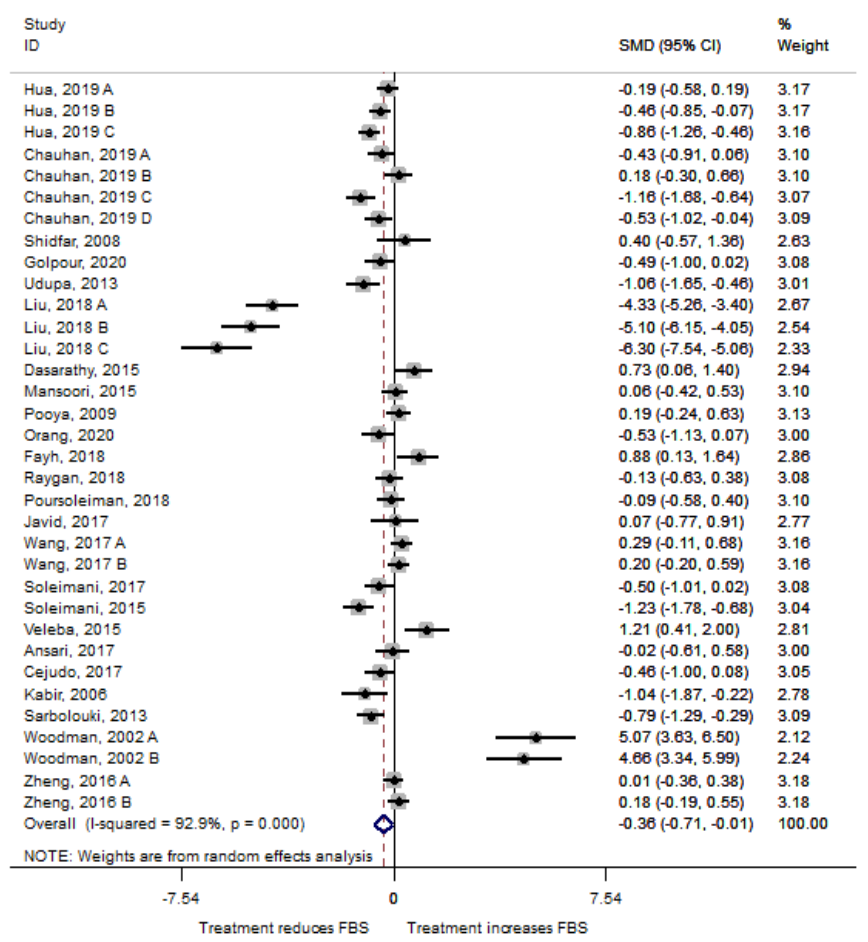

(B)

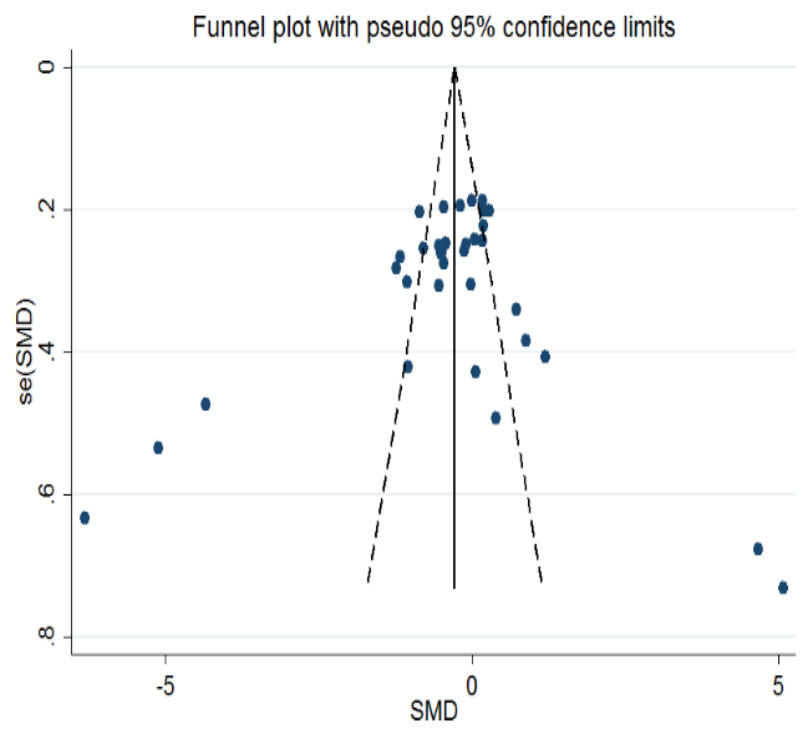

Figure 2. (A) The effect of omega-3 on FBS; (B) funnel plot examining the publication bias of FBS and $n$-3 supplementation.

(A)

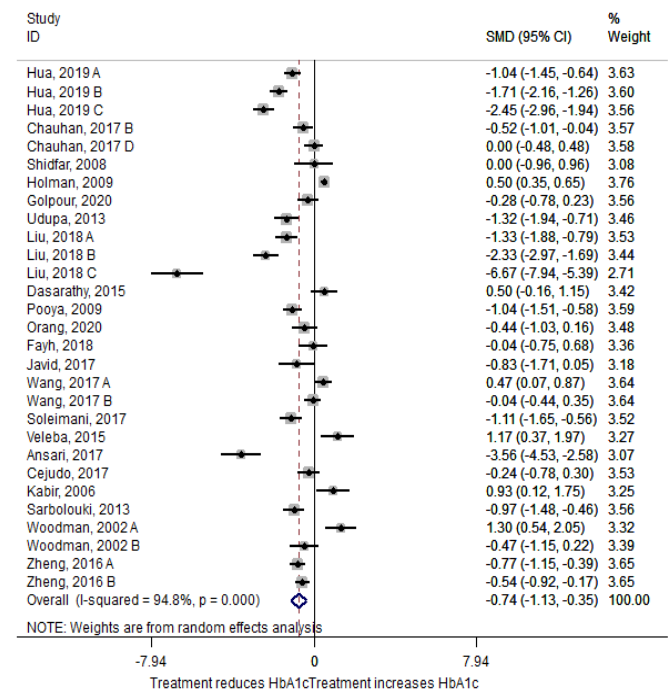

(B)

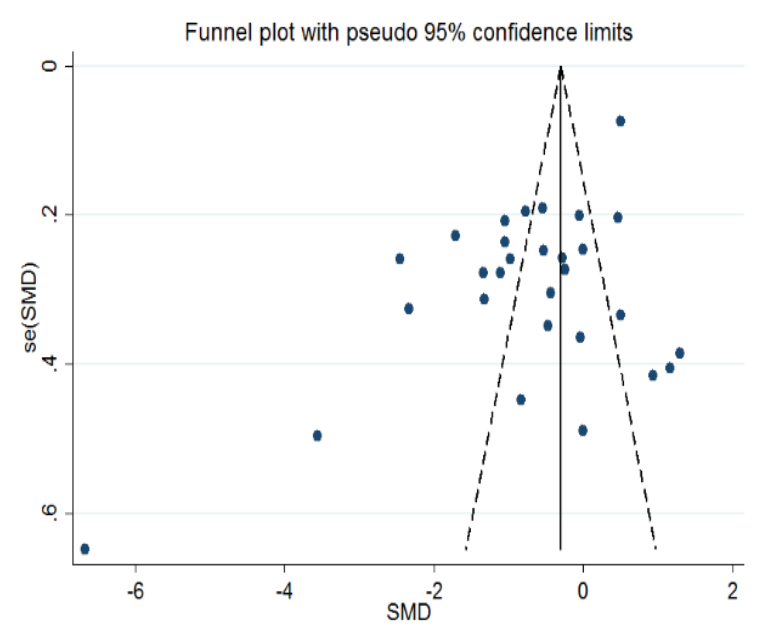

Figure 3. (A) The effect of $n-3$ on $\mathrm{HbA1c}$; (B) funnel plot examining the publication bias of $\mathrm{HbA} 1 \mathrm{c}$ and $n-3$ supplementation.

\section{HOMA.IR}

The common SMD from 13 studies was -0.58 (95\% CI: -1.13 to $-0.03, p=0.038)$ based on a random effect model, with significant heterogeneity between studies $\left(\mathrm{I}^{2}=95.6 \%\right.$, $p=0.00$ ) (Figure 4A). Further investigation detected 5 outliers with large effect sizes (Hua, 2019 C, SMD = -3.28; Liu, 2018 A, SMD = 3.50; Liu, 2018 B, SMD = 2.17; Liu, 2018 C, $\mathrm{SMD}=-3.85 ;$ Ansari, 2017, SMD = -2.21), these were therefore removed from any further 
analyses. This resulted in a reduction in effect size (SMD $=-0.38,95 \%$ CI: -0.75 to -0.01 ), but heterogeneity remained significant although considerable reduction in heterogeneity was observed $\left(\mathrm{I}^{2}=88.5 \%, p=0.00\right)$. According to the shape of funnel plot, we considered that there was no obvious publication bias among the included studies (Figure 4B).

(A)

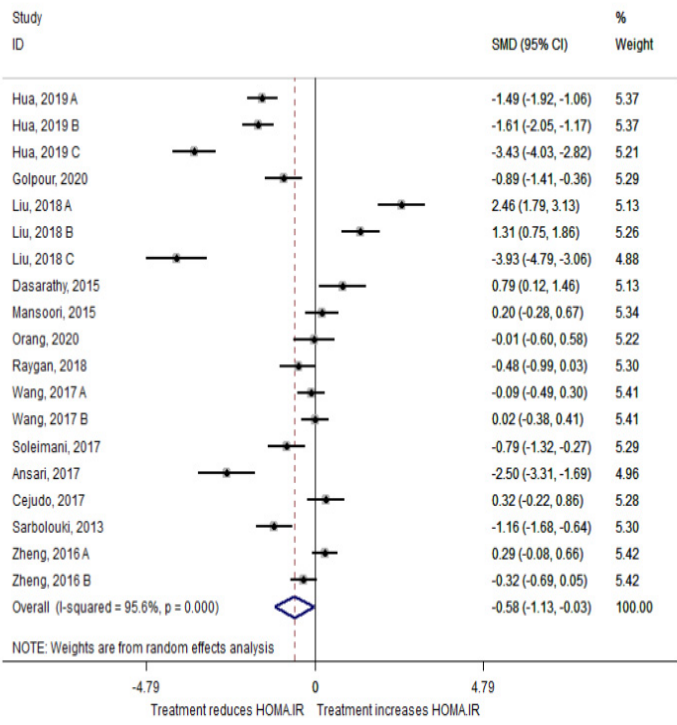

(B)

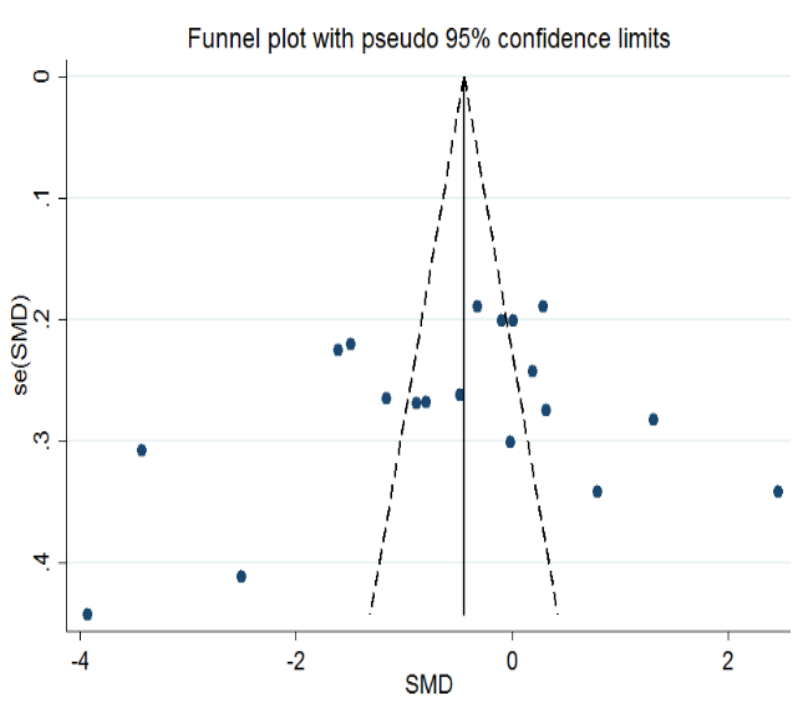

Figure 4. (A) The effect of $n$-3 on HOMA.IR; (B) funnel plot examining the publication bias of HOMA.IR and n-3 supplementation.

Sub-group analysis of different dosage of $n-3(<1000,1000-2000$, and $>2000 \mathrm{mg} / \mathrm{d})$ showed that $n-3$ consumption of $1000-2000 \mathrm{mg} / \mathrm{d}$ could significantly reduce FBS level and HOMA.IR; however, the reduction in supplementation for less than $1000 \mathrm{mg} / \mathrm{d}$ and more than $2000 \mathrm{mg} / \mathrm{d}$ was not significant. The reduction in HbA1c level was significant at all the 3 dose sub-groups. Moreover, sub-group analysis of duration of $n-3$ consumption ( $\leq 8$ week $/>8$ week) showed that $n-3$ consumption for more than 8 weeks could significantly reduce FBS level and HOMA.IR, but the reduction in $\mathrm{HbA1c}$ level was significant at both $\leq 8$ and $>8$ weeks (Table 2 ).

Table 2. Pooled estimates of $n-3$ effects on glycemic factors within dosage and duration subgroups.

\begin{tabular}{|c|c|c|c|c|c|c|}
\hline Variable & Group & $\begin{array}{c}\text { No. of } \\
\text { Comparisons }\end{array}$ & SMD $(95 \%$ CI $)$ & $p$-Value & $I^{2}(\%)$ & $p$-Heterogeneity \\
\hline \multirow{8}{*}{ FBS } & Total & 34 & $-0.36(-0.71,-0.01)$ & 0.047 & 92.9 & 0.000 \\
\hline & \multicolumn{6}{|c|}{ Intervention dosage (mg/d) } \\
\hline & $\leq 1000$ & 8 & $-0.20(-0.83,0.42)$ & 0.084 & 40.9 & 0.084 \\
\hline & $1000-2000$ & 13 & $-0.33(-0.57,-0.09)$ & $0.008 *$ & 69.0 & 0.000 \\
\hline & $\geq 2000$ & 13 & $-1.40(-1.42,0.63)$ & 0.448 & 96.9 & 0.000 \\
\hline & \multicolumn{6}{|c|}{ Intervention duration (w) } \\
\hline & $\leq 8$ & 14 & $-0.21(-0.96,0.54)$ & 0.588 & 95.6 & 0.000 \\
\hline & $>8$ & 20 & $-0.40(-0.75,-0.05)$ & $0.026^{*}$ & 92.9 & 0.000 \\
\hline
\end{tabular}


Table 2. Cont.

\begin{tabular}{|c|c|c|c|c|c|c|}
\hline Variable & Group & $\begin{array}{c}\text { No. of } \\
\text { Comparisons }\end{array}$ & SMD $(95 \%$ CI $)$ & $p$-Value & $I^{2}(\%)$ & $p$-Heterogeneity \\
\hline \multirow{8}{*}{$\mathrm{HbA1c}$} & Total & 29 & $-0.74(-1.13,-0.35)$ & 0.047 & 94.8 & 0.000 \\
\hline & \multicolumn{6}{|c|}{ Intervention dosage (mg/d) } \\
\hline & $\leq 1000$ & 5 & $-0.66(-1.11,-0.20)$ & $0.005 *$ & 68.4 & 0.013 \\
\hline & $1000-2000$ & 11 & $-0.75(-1.37,-0.14)$ & $0.016^{*}$ & 95.9 & 0.000 \\
\hline & $\geq 2000$ & 13 & $-0.81(-1.58,-0.03)$ & $0.042 *$ & 95.4 & 0.000 \\
\hline & \multicolumn{6}{|c|}{ Intervention duration $(\mathrm{w})$} \\
\hline & $\leq 8$ & 10 & $-0.69(-1.29,-0.08)$ & $0.025 *$ & 90.4 & 0.000 \\
\hline & $>8$ & 19 & $-0.77(-1.25,-0.29)$ & $0.002 *$ & 95.3 & 0.000 \\
\hline \multirow{8}{*}{ HOMA.IR } & Total & 19 & $-0.58(-1.13,-0.35)$ & 0.038 & 95.6 & 0.000 \\
\hline & \multicolumn{6}{|c|}{ Intervention dosage (mg/d) } \\
\hline & $\leq 1000$ & 3 & $0.32(-0.96,0.32)$ & 0.324 & 77.5 & 0.012 \\
\hline & $1000-2000$ & 8 & $-0.93(-1.71,-0.16)$ & $0.019 *$ & 95.6 & 0.000 \\
\hline & $\geq 2000$ & 8 & $-0.33(-1.40,0.74)$ & 0.546 & 96.6 & 0.000 \\
\hline & \multicolumn{6}{|c|}{ Intervention duration $(\mathrm{w})$} \\
\hline & $\leq 8$ & 5 & $0.16(-1.28,1.60)$ & 0.828 & 97.6 & 0.000 \\
\hline & $>8$ & 14 & $-0.84(-1.42,-0.26)$ & $0.005 *$ & 94.5 & 0.000 \\
\hline
\end{tabular}

\subsubsection{Lipid Profile}

TG

The common SMD from 17 studies was -0.27 (95\% CI: -0.37 to $-0.18, p=0.00$ ) based on a random effect model, with no heterogeneity between studies $\left(\mathrm{I}^{2}=0.0 \%, p=0.975\right)$ (Figure 5A). Furthermore, according to the shape of funnel plot, we considered that there was no obvious publication bias among the included studies (Figure 5B).

(A)

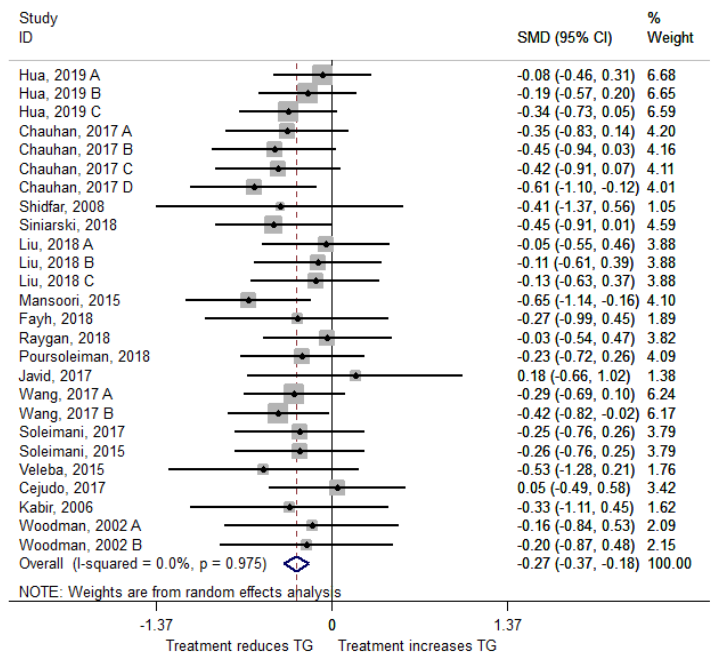

(B)

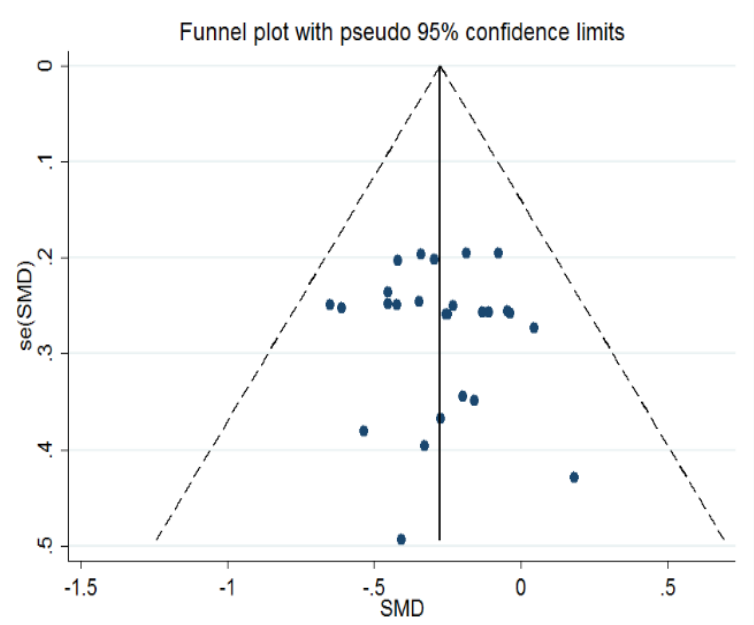

Figure 5. (A) The effect of $n-3$ on TG; (B) funnel plot examining the publication bias of TG and $n-3$ supplementation.

Cholesterol

The common SMD from 20 studies was -0.60 (95\% CI: -0.88 to $-0.32, p=0.00$ ) based on a random effect model, with significant heterogeneity between studies $\left(\mathrm{I}^{2}=90.8 \%\right.$, 
$p=0.00$ ) (Figure 6A). Further investigation detected 7 outliers with large effect sizes (Hua, 2019 B, SMD = -2.57; Hua, 2019 C, SMD = -3.50; Siniarski, 2018, SMD = -4.97; Liu, 2018 $\mathrm{B}, \mathrm{SMD}=-2.60$; Liu, $2018 \mathrm{C}, \mathrm{SMD}=-2.51$; Poursoleiman, 2018, SMD = 3.09; Soleimani, 2017 , SMD $=-3.61$ ), therefore they were removed from the analysis. Removing these studies resulted in a reduction in effect size ( $\mathrm{SMD}=-0.35,95 \% \mathrm{CI}:-0.58$ to -0.13 ), but heterogeneity still remained significant although a reduction in heterogeneity was observed $\left(\mathrm{I}^{2}=81.3 \%, p=0.00\right)$. According to the shape of the funnel plot, we considered that there was no obvious publication bias among the included studies with cholesterol as an outcome measure (Figure 6B).

(A)

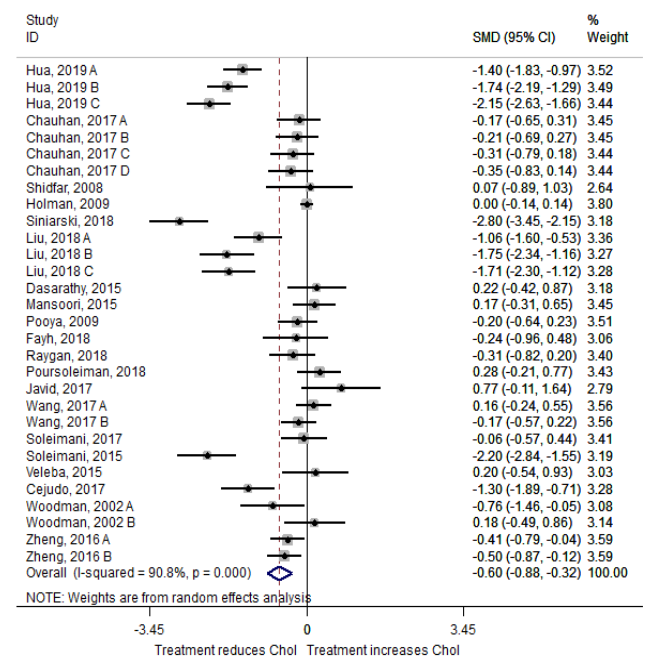

(B)

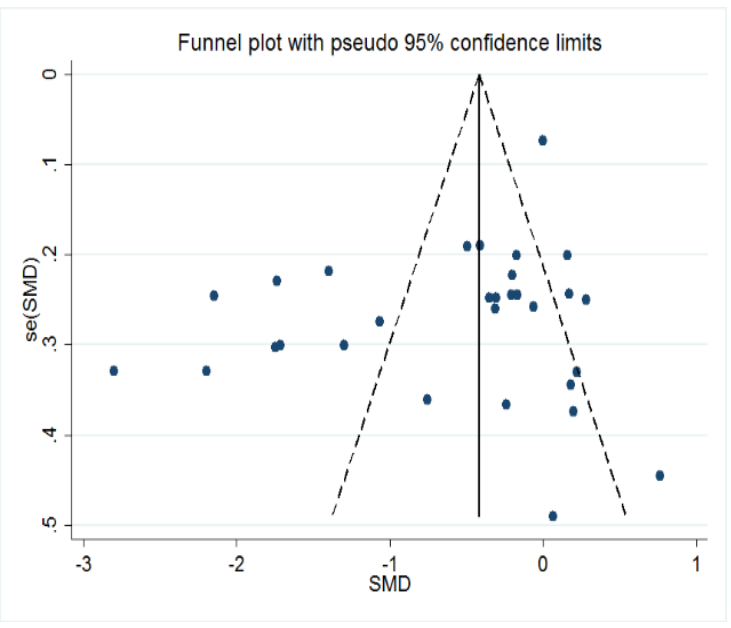

Figure 6. (A) The effect of $n-3$ on Chol; (B) funnel plot examining the publication bias of Chol and $n-3$ supplementation.

\section{LDL}

The common SMD from 20 studies was -0.54 (95\% CI: -0.85 to $-0.23, p=0.001)$ based on a random effect model, with significant heterogeneity between studies $\left(\mathrm{I}^{2}=91.8 \%\right.$, $p=0.00$ ) (Figure 7A). Further investigation detected 7 outliers with large effect sizes (Hua, 2019 C, SMD = -3.65; Siniarski, 2018, SMD = -4.75; Liu, 2018 A, SMD = -2.98; Liu, 2018 B, SMD = -4.67; Liu, 2018 C, SMD = -4.39; Poursoleiman, 2018, SMD = 2.96; Javid, $2017, \mathrm{SMD}=2.82)$. Therefore, these studies were removed from further analyses in this outcome. The removal of these studies resulted in a reduction in effect size (SMD $=-0.22$, $95 \%$ CI: -0.42 to -0.03$)$, but heterogeneity remained significant although a reduction in heterogeneity was observed $\left(\mathrm{I}^{2}=74.7 \%, p=0.00\right)$.

Publication bias regarding studies of LDL was observed using visual inspection of funnel plot, however, the results of a Begg's and Egger's asymmetry test were not significant $(p>0.05)$. Trim and fill analysis was therefore conducted to correct the bias imputing three hypothetical studies. The results were significant even after trim and fill analysis (SMD $=-0.662 ; 95 \% \mathrm{CI}:-0.96$ to $-0.35 ; p=0.00$ ) (Figure $7 \mathrm{~B}$ ). 
(A)

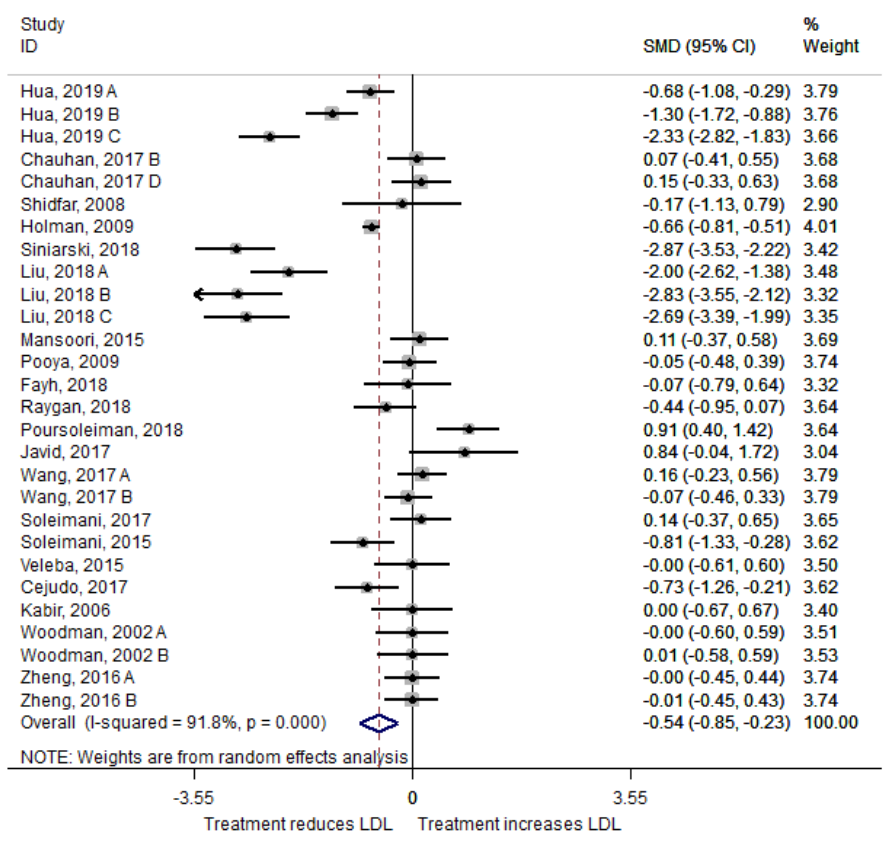

(B)

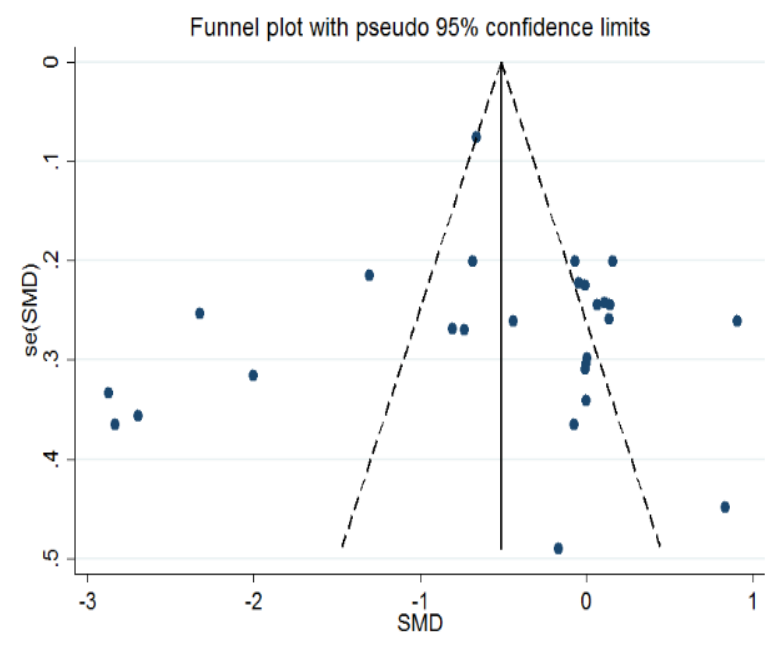

Figure 7. (A) The effect of $n-3$ on LDL; (B) funnel plot examining the publication bias of LDL and $n-3$ supplementation.

HDL

The common SMD from 20 studies was 0.60 (95\% CI: 0.23 to $0.96, p=0.001)$ based on a random effect model, with significant heterogeneity between studies $\left(\mathrm{I}^{2}=94.0 \%, p=0.00\right)$ (Figure 8A). Further investigation detected 7 outliers with large effect sizes (Hua, 2019 B, SMD = 2.44; Hua, 2019 C, SMD = 2.92; Holman, 2009, SMD = 2.50; Liu, 2018 B, SMD = 2.41; Liu, 2018 C, SMD = 5.76; Poursoleiman, 2018, SMD = -2.36; Javid, 2017, SMD = -2.50). These studies were therefore removed from further analyses of the HDL as an outcome. Removal of these studies resulted in a reduction in effect size (SMD $=0.32,95 \%$ CI: 0.14 to 0.51 ), but heterogeneity still remained significant although considerable reduction in heterogeneity was observed $\left(\mathrm{I}^{2}=64.0 \%, p=0.00\right)$. According to the shape of funnel plot, we considered that there was no obvious publication bias among the included studies (Figure 8B).

Sub-group analysis of different dosage of $n-3$ consumption $(<1000,1000-200$, or $>2000 \mathrm{mg} / \mathrm{d}$ ) showed that $n-3$ consumption in all the 3 dose sub-groups could significantly reduce TG and total-cholesterol levels. LDL and HDL levels were also significantly changed by $n-3$ consumption of more than $1000 \mathrm{mg} / \mathrm{d}$. Moreover, sub-group analysis of duration of $n$ - 3 consumption ( $\leq 8$ week/ $>8$ week) showed that $n-3$ consumption for both $\leq 8$ and $>8$ weeks could significantly reduce TG and total cholesterol levels and increase HDL level; however, the significant reduction in LDL level occurred only when $n-3$ was consumed for more than 8 weeks (Table 3). 
(A)

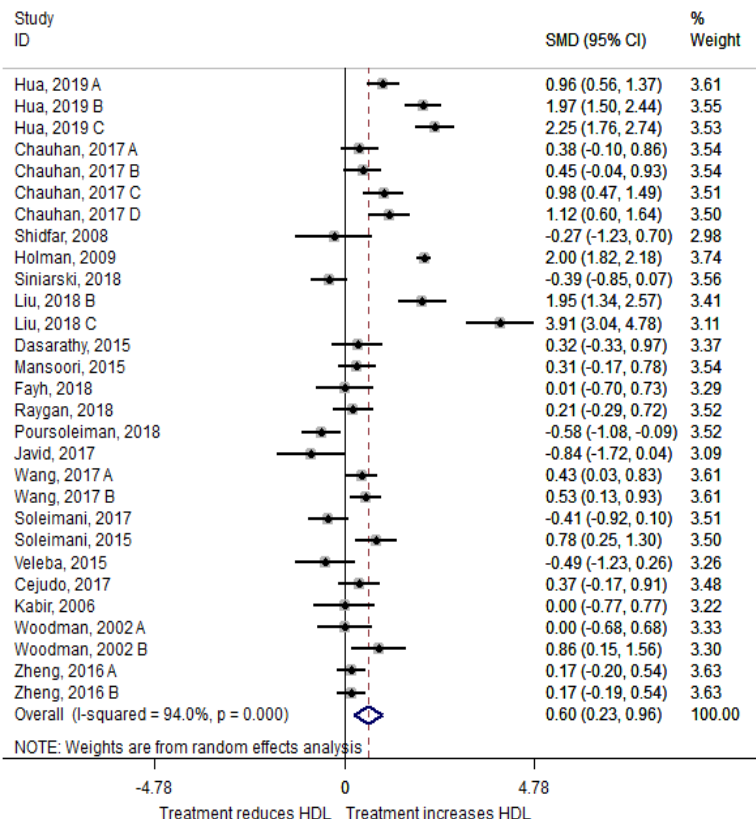

(B)

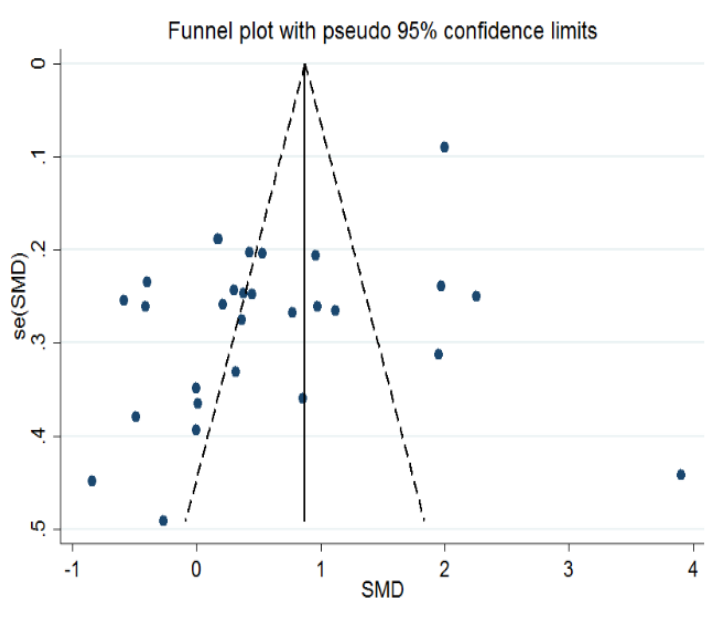

Figure 8. (A): The effect of $n-3$ on HDL; (B) funnel plot examining the publication bias of HDL and $n-3$ supplementation.

Table 3. Pooled estimates of $n$-3 effects on lipid profile within dosage and duration subgroups.

\begin{tabular}{|c|c|c|c|c|c|c|}
\hline Variable & Group & $\begin{array}{c}\text { No. of } \\
\text { Comparisons }\end{array}$ & SMD $(95 \%$ CI $)$ & $p$-Value & $I^{2}(\%)$ & $p$-Heterogeneity \\
\hline \multirow{8}{*}{ TG } & Total & 26 & $-0.27(-0.37,-0.18)$ & 0.038 & 0.0 & 0.958 \\
\hline & \multicolumn{6}{|c|}{ Intervention dosage (mg/d) } \\
\hline & $\leq 1000$ & 7 & $-0.23(-0.43,0.03)$ & $0.023 *$ & 0.0 & 0.851 \\
\hline & $1000-2000$ & 10 & $-0.32(-0.47,-0.17)$ & $0.000 *$ & 0.0 & 0.621 \\
\hline & $\geq 2000$ & 9 & $-0.24(-0.42,-0.07)$ & $0.006^{*}$ & 0.0 & 0.958 \\
\hline & \multicolumn{6}{|c|}{ Intervention duration $(\mathrm{w})$} \\
\hline & $\leq 8$ & 13 & $-0.23(-0.37,-0.08)$ & $0.002 *$ & 0.0 & 0.909 \\
\hline & $>8$ & 13 & $-0.23(-0.45,-0.18)$ & $0.000 *$ & 0.0 & 0.904 \\
\hline \multirow{8}{*}{ CHOL } & Total & 30 & $-0.60(-0.88,-0.32)$ & 0.038 & 90.8 & 0.000 \\
\hline & \multicolumn{6}{|c|}{ Intervention dosage (mg/d) } \\
\hline & $\leq 1000$ & 7 & $-0.62(-1.16,-0.08)$ & $0.024 *$ & 85.3 & 0.000 \\
\hline & $1000-2000$ & 13 & $-0.66(-1.14,-0.18)$ & $0.007^{*}$ & 94.2 & 0.000 \\
\hline & $\geq 2000$ & 10 & $-0.49(-0.95,-0.03)$ & $0.037 *$ & 86.0 & 0.000 \\
\hline & \multicolumn{6}{|c|}{ Intervention duration $(\mathrm{w})$} \\
\hline & $\leq 8$ & 13 & $-0.50(-0.93,-0.07)$ & $0.024 *$ & 88.1 & 0.000 \\
\hline & $>8$ & 17 & $-0.67(-1.05,-0.29)$ & $0.001 *$ & 92.3 & 0.000 \\
\hline
\end{tabular}


Table 3. Cont.

\begin{tabular}{|c|c|c|c|c|c|c|}
\hline Variable & Group & $\begin{array}{c}\text { No. of } \\
\text { Comparisons }\end{array}$ & SMD $(95 \%$ CI $)$ & $p$-Value & $I^{2}(\%)$ & $p$-Heterogeneity \\
\hline \multirow{8}{*}{ LDL } & Total & 28 & $-0.54(-0.85,-0.23)$ & 0.047 & 91.8 & 0.000 \\
\hline & \multicolumn{6}{|c|}{ Intervention dosage (mg/d) } \\
\hline & $\leq 1000$ & 6 & $-0.31(-0.65,0.03)$ & 0.073 & 58.2 & 0.035 \\
\hline & $1000-2000$ & 12 & $-0.51(-1.01,-0.02)$ & $0.042 *$ & 93.9 & 0.000 \\
\hline & $\geq 2000$ & 10 & $-0.72(-1.38,-0.07)$ & $0.029 *$ & 93.1 & 0.000 \\
\hline & \multicolumn{6}{|c|}{ Intervention duration $(\mathrm{w})$} \\
\hline & $\leq 8$ & 12 & $-0.43(-0.98,0.13)$ & 0.132 & 91.8 & 0.000 \\
\hline & $>8$ & 16 & $-0.62(-1.01,-0.23)$ & $0.002 *$ & 92.2 & 0.000 \\
\hline \multirow{8}{*}{ HDL } & Total & 29 & $0.60(0.23,0.96)$ & 0.001 & 94.0 & 0.000 \\
\hline & \multicolumn{6}{|c|}{ Intervention dosage (mg/d) } \\
\hline & $\leq 1000$ & 7 & $0.27(-0.01,0.55)$ & 0.063 & 48.8 & 0.069 \\
\hline & $1000-2000$ & 13 & $0.63(0.04,1.22)$ & $0.036 *$ & 96.0 & 0.000 \\
\hline & $\geq 2000$ & 9 & $0.81(0.14,1.49)$ & $0.001 *$ & 91.1 & 0.000 \\
\hline & \multicolumn{6}{|c|}{ Intervention duration (w) } \\
\hline & $\leq 8$ & 12 & $0.52(0.03,1.01)$ & $0.036 *$ & 88.9 & 0.000 \\
\hline & $>8$ & 17 & $0.65(0.15,1.16)$ & $0.012 *$ & 95.5 & 0.000 \\
\hline
\end{tabular}

\subsubsection{Inflammatory Markers}

TNF- $\alpha$

The common SMD from 4 studies was -0.13 (95\% CI: -0.75 to $0.48, p=0.668$ ) based on a random effect model, with significant heterogeneity between studies $\left(\mathrm{I}^{2}=78.8 \%\right.$, $p=0.003$ ) (Figure 9A). Further investigation detected no outliers.

(A)

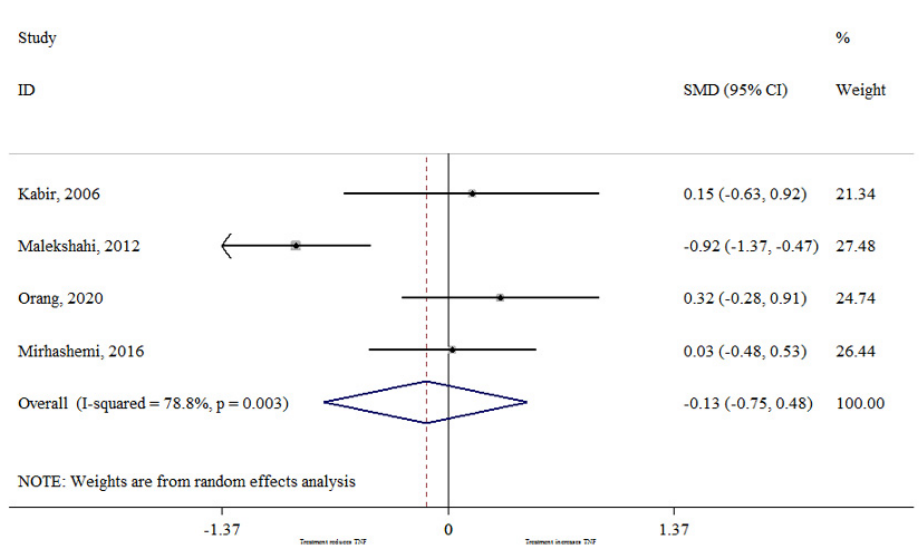

(B)

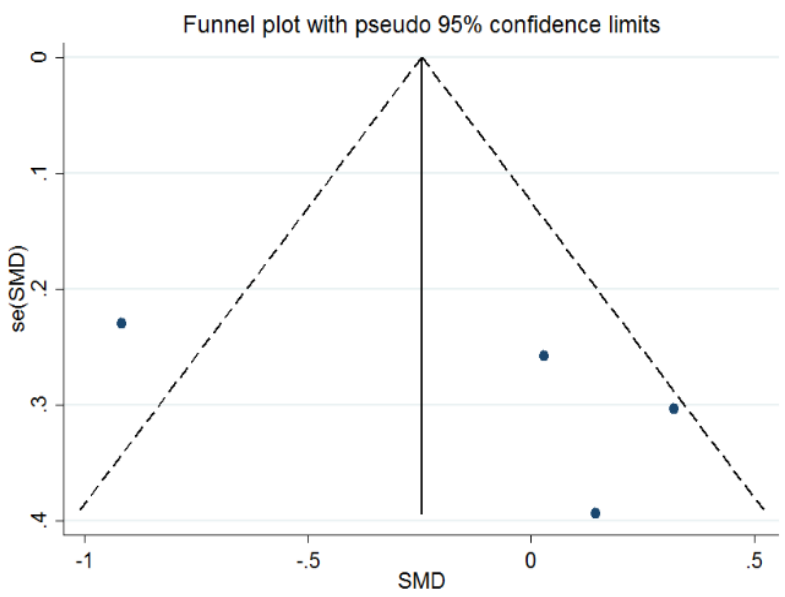

Figure 9. (A) The effect of $n-3$ on TNF- $\alpha$; (B) funnel plot examining the publication bias of TNF- $\alpha$ and $n-3$ supplementation.

Publication bias regarding studies of TNF- $\alpha$ was observed using visual inspection of funnel plot, however, the results for Begg's and Egger's asymmetry test were not significant $(p>0.05)$. Therefore, trim and fill analysis were conducted to correct the bias imputing two hypothetical studies. The results were non-significant even after trim and fill analysis $(\mathrm{SMD}=-0.482 ; 95 \% \mathrm{CI}:-1.05$ to $0.08 ; p=0.096$ ) (Figure $9 \mathrm{~B})$. 


\section{CRP}

The common SMD from 6 studies was -0.72 (95\% CI: -1.70 to $0.27, p=0.156$ ) based on a random effect model, with significant heterogeneity between studies $\left(\mathrm{I}^{2}=95.1 \%\right.$, $p=0.00$ ) (Figure 10A). Further investigation detected no outliers. Furthermore, according to the shape of the funnel plot, it was considered that there was no obvious publication bias among the included studies (Figure 10B).

(A)

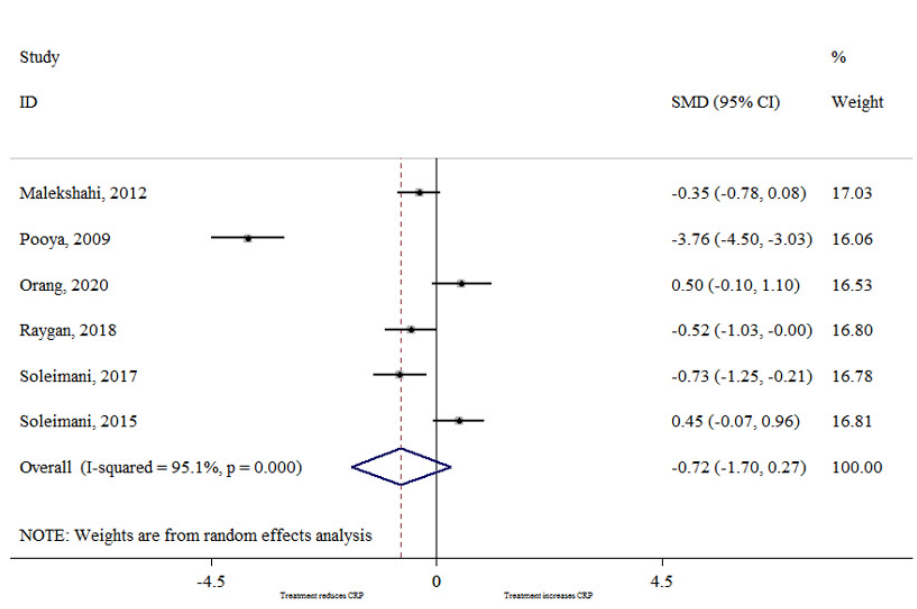

(B)

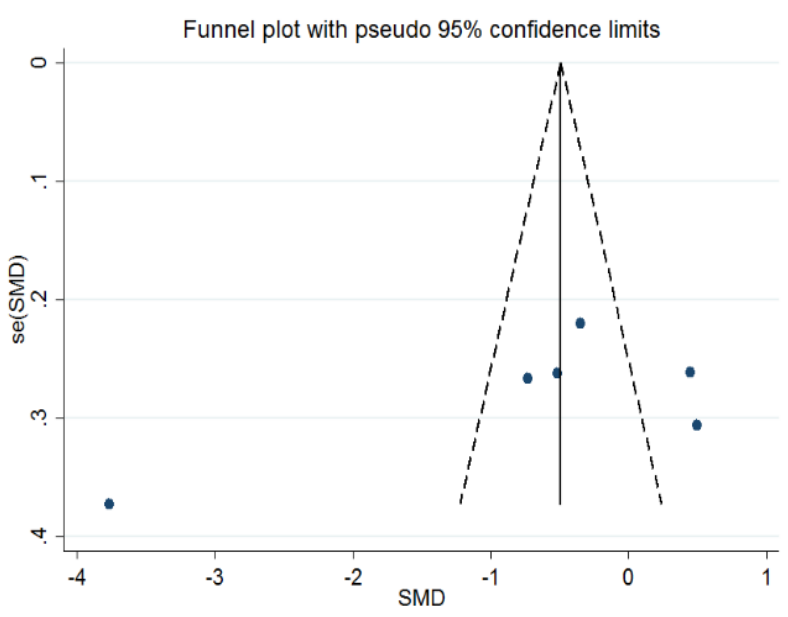

Figure 10. (A) The effect of $n-3$ on CRP; (B) funnel plot examining the publication bias of CRP and $n-3$ supplementation.

\subsubsection{Anthropometric Parameters}

\section{Weight}

The common SMD from 13 studies was -0.09 (95\% CI: -0.24 to $0.07, p=0.280)$ based on a random effect model, with no heterogeneity between studies $\left(\mathrm{I}^{2}=0.0 \%, p=0.989\right)$ (Figure 11A).

(A)

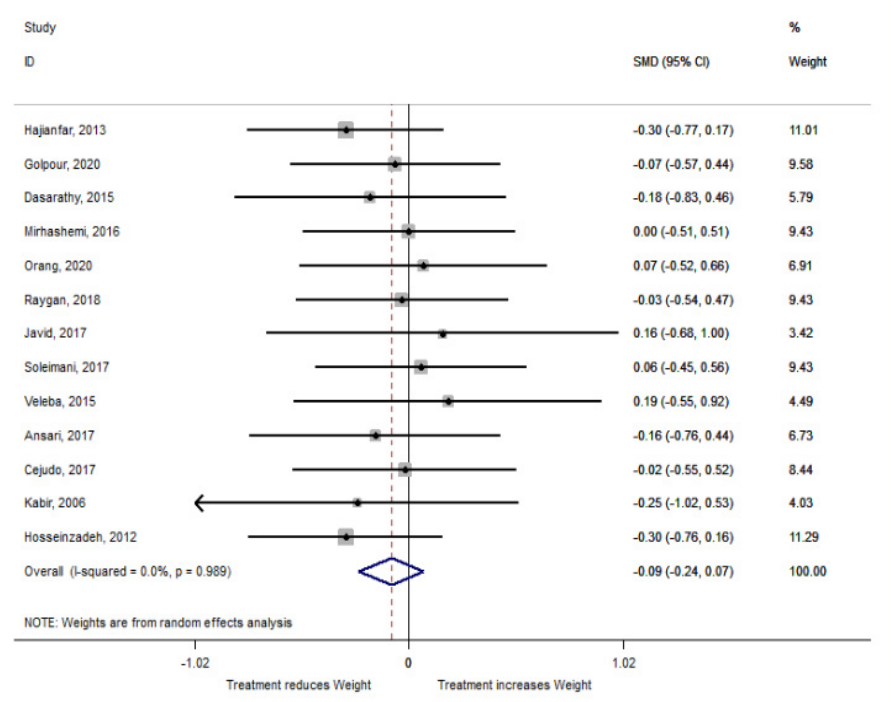

(B)

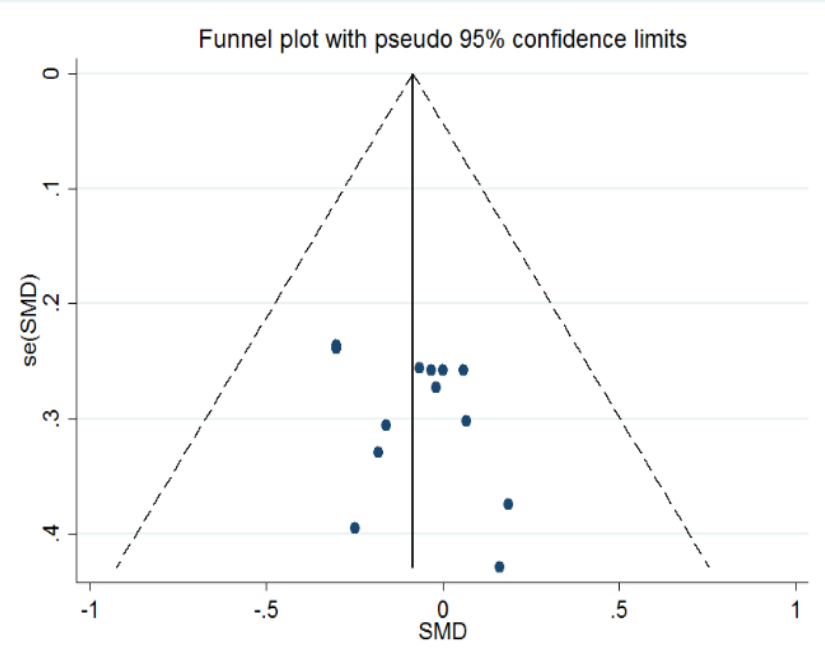

Figure 11. (A) The effect of $n-3$ on weight; (B) funnel plot examining the publication bias of weight and $n$ - 3 supplementation. 
Publication bias regarding studies of weight was observed using visual inspection of funnel plot, however, the results for Begg's and Egger's asymmetry test were not significant $(p>0.05)$. Trim and fill analysis was conducted to correct the bias imputing two hypothetical studies. The results were not significant even after trim and fill analysis $(\mathrm{SMD}=-0.108 ; 95 \% \mathrm{CI}:-0.25$ to $0.042 ; p=0.157$ ) (Figure 11B).

\section{BMI}

The common SMD from 12 studies was -0.13 (95\% CI: -0.29 to $0.02, p=0.093$ ) based on a random effect model, with no heterogeneity between studies $\left(\mathrm{I}^{2}=0.0 \%, p=0.930\right)$ (Figure 12A). According to the shape of funnel plot, we considered that there was no obvious publication bias among the included studies (Figure 12B).

(A)

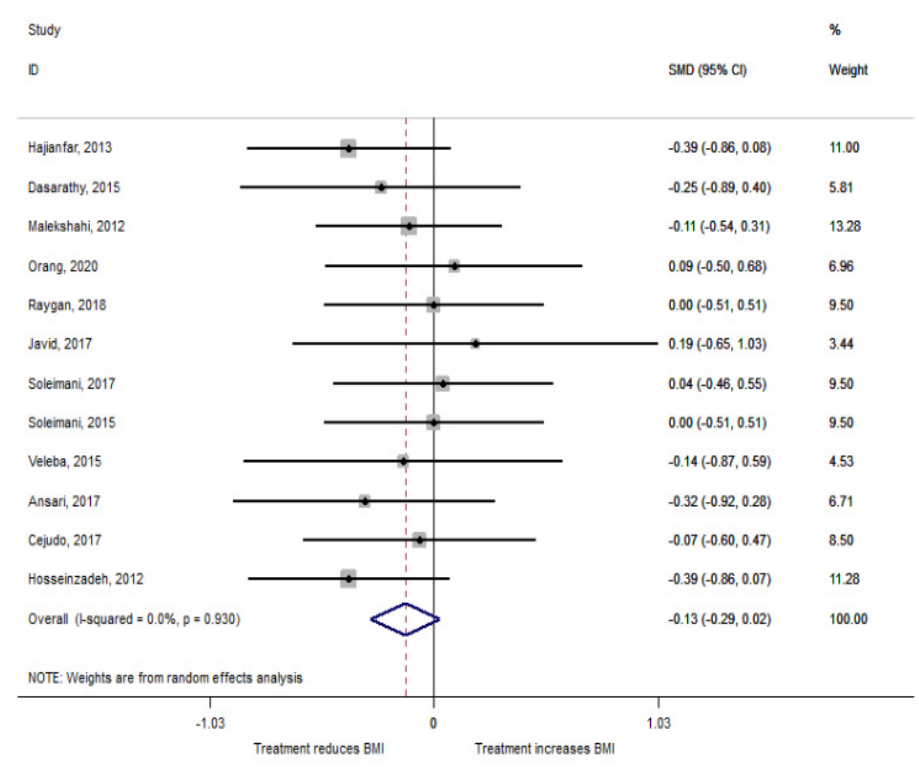

(B)

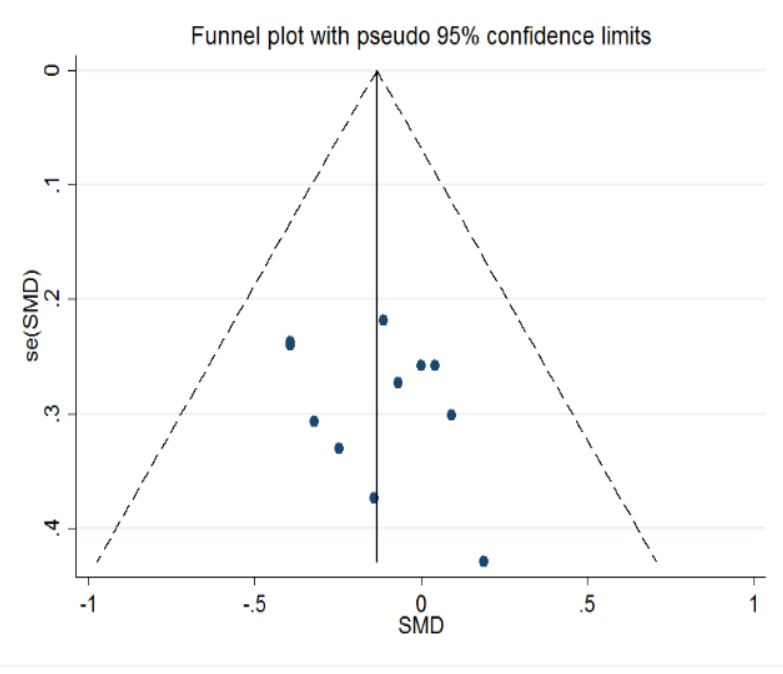

Figure 12. (A) The effect of $n-3$ on BMI; (B) funnel plot examining the publication bias of BMI and $n-3$ supplementation.

\section{Discussion}

The beneficial effects of $n-3$ supplementation on metabolic biomarkers have been previously investigated in several studies, including our own, in T2DM $[25,43,44]$. The present review has systematically analyzed RCTs to further clarify the effects of $n-3$ consumption on glycemic factors, body weight, lipid profile, and inflammatory biomarkers in patients with T2DM. The results show that consuming $n-3$ significantly improve glycemic factors (FBS, HbA1c, and HOMA.IR) and lipid profile (TG, total cholesterol, LDL, and HDL) in patients with T2DM. However, in the small number of sample studies investigated reductions in weight, BMI, and inflammatory biomarkers (TNF- $\alpha$ and CRP) were not statistically significant.

It has long been known that membrane phospholipid PUFAs composition is associated with insulin sensitivity [45]. The beneficial effects of $n-3$ fatty acids on glycemic control and glucose homeostasis are likely to involve several mechanisms. With increased incorporation of $n-3$ fatty acids into cellular membranes, via supplementation, membrane fluidity and several cell membrane and intracellular receptors, which regulate cellular signaling and gene expression, can be affected leading to increased insulin sensitivity [46]. For example, EPA and DHA can increase GLUT1 and GLUT4 translocation respectively and the transport of glucose [47,48]. Furthermore, $n$-3 fatty acids may improve glucose homeostasis through regulating inflammation $[48,49]$. In addition, studies in animal models have shown that $n-3$ fatty acids improve insulin sensitivity and glucose homeostasis by 
influencing the insulin signaling pathway [50-52]. The results of the present meta-analysis show that $n-3$ supplementation can significantly improve the glycemic response in patients with T2DM. The results are consistent with those of a previous meta-analysis conducted by O'Mahoney et al. [43]. They showed that $n-3$ PUFAs supplementation can produce favorable improvement in glycaemia. Importantly, in the present investigation, in a subgroup analysis, we found that consuming a dose of 1000-2000 mg/d $n-3$ supplement for more than 8 weeks can improve the FBS level and HOMA.IR index. A previous study demonstrated that $n-3$ fatty acids supplementation at high doses (12 $\mathrm{g}$ of fish oil for 6 weeks) increased glycerol gluconeogenesis by $32 \%$, which could contribute to a deterioration of glycemic control during long-term treatment [53]. Therefore, we suggest based on our analysis the optimal dosage of $n-3$ supplementation, for improving glycemic and related parameters is $1000-2000 \mathrm{mg} / \mathrm{d}$.

It is well established that T2DM is associated with dyslipidemia (4) and that $n-3$ intake has long been indicated in the treatment of hyperlipidemia [30,31]. As cell membrane fatty acids play an important role in signal transduction, and $n-3$ fatty acids are capable of modifying gene expression, it is thought that the dramatic lipid-altering effects of $n-3$ fatty acids are mediated via this mechanism [54]. More specifically, $n-3$ fatty acids can modulate the function of peroxisome proliferator-activated receptors (PPARs) and sterol regulatory element-binding proteins (SREBPs), both of which are involved in lipid homeostasis [55] and have been reviewed in detail elsewhere [54]. We observed a significant reduction in triglycerides, total cholesterol, and LDL levels and significant increase in HDL level in response to $n-3$ supplementation in T2DM. These findings are similar to the results of previous meta-analyses [56-59]. Our sub-group analysis however also revealed that $n-3$ supplementation of greater than $1000 \mathrm{mg} / \mathrm{d}$ for more than 8 weeks can significantly improve the lipid profile in patients with T2DM.

In relation to inflammation TNF- $\alpha$ and IL- 6 can impair insulin signaling and action by post-translational modulation of insulin receptor substrates [60]. Furthermore, TNF- $\alpha$ can induce lipolysis in fat cells leading to increased free fatty acids [61] and the adipocytokines have inflammatory effects, e.g., pro-inflammatory resistin and leptin $[25,62]$. Clinical trials indicate that $n-3$ fatty acid supplementation can affect the serum concentrations of inflammatory biomarkers, including TNF- $\alpha$ and serum CRP levels. A direct mechanism through which n-3 PUFA can decrease inflammation includes rapid effects on the regulation of transcription factors [63,64], and indirect modes of actions including the production of, e.g., five-series eicosanoids [65] and inflammation-resolving lipid mediators and suppression of acute phase reactants $[66,67]$. In a study conducted by Rangel-Huerta et al., they reviewed 26 RCTs which supplemented $n-3$ FAs over 10 years; ten of the reported trials were undertaken in healthy and the remainder in chronic diseases participants [68]. In the studies of healthy participants, they found that $n-3$ supplementation generally had no effect on inflammatory biomarkers, which may have been due to low circulating levels. Among the cardiovascular disease patients, the level of CRP and IL-6 was generally decreased after 12 weeks of the $n-3$ supplement. In contrast in the large meta-analysis by Li et al. [69] which included 68 RCTs (total of 4601 subjects) they found that marine-derived $n$-3 PUFA (EPA, DHA, fish oil) significantly decreased CRP, TNF- $\alpha$ and IL-6 in healthy (particularly older subjects) and in patients with chronic non-autoimmune disease. They also reported that the effects were associated with treatment dose and duration. In the current analysis however, we found that $n-3$ supplementation did not significantly decrease inflammatory biomarkers. This may in-part be due to low number of included studies, the variable levels of inflammatory biomarkers reported, use of drug treatments, background diet and relatively low dose used in some of the studies. This meta-analysis and other studies discussed consistently show that $n-3$ supplementation effects on metabolic or inflammatory markers depends on dose and time. Most likely this is a function of the time required to fully incorporate fatty acids into membrane phospholipids and affect dysregulated homeostatic mechanisms. 
There is evidence that increased intakes of $n-3$ fatty acids can reduce body fat in humans, but human studies are relatively few and have generally been conducted over short time periods with small sample sizes [70]. The mechanisms by which $n-3$ PUFA reduce body fat are not well understood. There is evidence from both human [71] and animal $[72,73]$ studies that suggest that these fatty acids may contribute to improvements in body composition by suppressing appetite and promoting apoptosis of adipocytes [73]. Moreover, there is considerable evidence from animal studies indicating that the effects of n-3 PUFA on body weight and body fat are mediated by altering the expression of genes involved in the regulation of fat metabolism in several tissues. However, the effect of $n-3$ supplementation on body weight and BMI was not significant in the present analysis. More studies to increase sample size, better controlled inclusion and exclusion criteria for weight or longer duration and higher dosage of $n-3$ supplementation might uncover significant effects of $n-3$ supplementation on weight in T2DM.

There have been several other meta-analysis studies of the effects of $n-3$ in T2DM. Chen et al. (2015) [74] reported no significant difference in glucose control between placebo and $n-3$ supplementation but did report beneficial effects on lipid profile in their metaanalysis. In the meta-analysis by Brown et al. (2019) [75] they found that neither $n-3, n-6$ or total PUFA supplementation affects the development or treatment of diabetes. Importantly Brown et al. investigated both diet intake and supplementation studies. It is well known that dietary intake analysis is not necessarily precise (in contrast our data were obtained directly from supplementation RCTs only) and they also state that their data included a high number of RCTs at risk of bias. In the meta-analysis undertaken by Natto et al. (2019) [76] they suggested that $n-3$ supplementation may improve metabolic or inflammatory markers, e.g., TNF- $\alpha$ in patients with diabetes or cardiovascular disease, but their data was not conclusive, and furthermore they did not explore the effects of dose or time. Gao et al. (2020) [77] in their meta-analysis found no effect of fish oil supplementation on glucose metabolism parameters but did observe a positive effect on lipid profile markers. The difference in glycemic parameters we observed in the present study may be linked to the different supplement sources included in our meta-analysis. Furthermore, in some of the RCTs included in previous studies there may have been dietary components that track with $n-3$ intake which could have disrupted any beneficial effects. We included a greater number of $n-3$ supplementation RCTs in our meta-analysis compared with most previous meta-analysis studies, which may also account for the glycemic parameter differences between some previous studies and present analysis.

The present study has some limitations. Firstly, the number of studies evaluating the effect of $n-3$ supplementation on inflammatory markers and body weight was low. Secondly, different $n-3$ fatty acids (parent ALA and it's metabolic products EPA and DHA) supplementation has been used in different studies i.e., marine-derived (EPA, DHA and fish oil) and plant-derived (ALA, flaxseed). Although it is generally accepted that ALA exerts its effects via conversion to EPA [78], it is also possible ALA has biological effects in T2DM without conversation to EPA [79]. Thirdly, significant heterogeneity was found in most of the analyzed parameters, and the source of the heterogeneity was not explored further. We also only used random-effects models to address heterogeneity, which may have affected the strength and extrapolation of our conclusions. In addition, it is becoming clear that the effects of $n$ - 3 fatty acids supplementation in T2DM populations differ depending on their ethnic and dietary backgrounds [44]. Finally, the effects of a more balanced intake of $n-3$ and $n-6$ PUFAs on metabolic and inflammatory biomarkers [45,79-82] with or without probiotics [83] on T2DM are also now warranted.

\section{Methods}

This study followed the Preferred Reporting Items for Systematic Reviews and MetaAnalyses (PRISMA) guidelines. The study protocol was registered prospectively in PROSPERO (CRD42021250440). 


\subsection{Search Strategy}

Online databases PubMed, Embase, Web of Science, and Science Direct were searched until 2021 for studies that investigated the effects of omega-3 supplementation on metabolic biomarkers and body weight in patients with T2DM. The following search terms were used: (Omega-3 OR $n$-3 OR fish oil) AND (diabetes OR type 2 diabetes OR T2D OR T2DM) AND (FBS OR fasting blood glucose OR glycemic OR glucose OR Insulin OR HOMA.IR OR A1c OR HbA1c OR lipid profile OR TG OR Cholesterol OR LDL OR HDL OR triglyceride OR CRP OR TNF- $\alpha$ OR weight OR BMI OR Body Mass Index). Our search was restricted to studies published in the English language.

\subsection{Study Selection and Inclusion and Exclusion Criteria}

The following criteria were used to identify eligible studies: (i) randomized placebocontrolled trials with either parallel or cross-over design, (ii) investigation of the effects of $n-3$ on glycemic factors in patients with T2DM, (iii) investigation of the effects of $n-3$ on lipid profile in patients with T2DM, (iv) investigation of the effects of $n-3$ on inflammatory biomarkers in patients with T2DM, (v) investigation of the effects of $n-3$ on BMI or body weight in patients with T2DM and (vi) providing sufficient information on the baseline and endtrial metabolic bio-markers, weight, and/or BMI in both $n-3$ and control groups. Exclusion criteria were (i) animal studies, (ii) observational studies, (iii) uncontrolled studies, and (iv) lack of sufficient/relevant information on the baseline or end-trial blood biomarkers.

\subsection{Data Extraction}

The following data were abstracted: (1) first author's name; (2) year of publication; (3) number of participants in the omega-3 and control groups; (4) dose of omega-3 supplement; and (5) treatment duration.

\subsection{Quality Assessment}

A systematic assessment of bias in the included studies was performed using the Cochrane criteria. The items used for the assessment of each study were as follows: adequacy of sequence generation, allocation concealment, blinding, addressing of dropouts (incomplete outcome data), selective outcome reporting, and other potential sources of bias. According to the recommendations of the Cochrane Handbook, a judgment of "yes" indicated a low risk of bias, while "no" indicated high risk of bias. Labeling an item as "unclear" indicated an unclear or unknown risk of bias.

\subsection{Statistical Analysis}

The mean changes (mean values and SD) in fasting blood sugar (FBS), glycated hemoglobulin (HbA1c), homeostatic model assessment of insulin resistance (HOMA.IR), insulin, malonaldehyde (MDA), c-reactive protein (CRP), tumor necrosis factor-alpha (TNF$\alpha$ ), triglycerides (TG), cholesterol, low density lipoprotein (LDL), high density lipoprotein (HDL), weight, and body mass index (BMI) for each study were calculated. Statistical analysis was conducted using Stata 16.0 (Stata Corp, College Station, Texas, USA). The heterogeneity among studies was evaluated by Cochran heterogeneity test and $\mathrm{I}^{2}$ statistic. $p$ values of $<0.05$ or $\mathrm{I}^{2}$ of $>50 \%$ indicated that heterogeneity existed among studies. Otherwise, homogeneity of those studies was indicated. The standardized mean difference (SMD) of each study along with its 95\% CI was calculated. Sensitivity analysis was carried out to check the influence of one single study removal on overall effect size. Additionally, funnel plots were conducted for assessing the publication bias of included literatures and we could assess the publication bias by seeing whether their shapes were of any obvious asymmetry. To find the studies with outlier SMD, a series of sensitivity analyses was conducted and in the case of being outlier a second meta-analysis was performed after removing the outlier study. 


\section{Conclusions}

The present meta-analysis and review found that $n-3$ supplementation can regulate the glycemic response and lipid profile in patients with T2DM. Furthermore $n-3$ supplementation may provide beneficial effects on inflammatory biomarkers and body weight if used at a specific dose and duration. The preferred dose and duration for patients with T2DM is $1000-2000 \mathrm{mg} / \mathrm{d}$ for more than 8 weeks. More studies are needed to fully evaluate the effect of the different types of $n-3$ fatty acids i.e., fish-oil, and EPA and DHA and plant-derived ALA supplements on T2DM metabolic and inflammatory biomarkers. The effectiveness of different doses and durations of such interventions in T2DM should be compared and should include T2DM populations with different dietary and ethnic backgrounds.

Author Contributions: Conceptualization L.K., L.S.H.; methodology and statistics L.K., L.S.H.; investigation and interpretation L.K., L.S.H.; writing original draft preparation L.K., L.S.H.; writing review and editing L.K., L.S.H., R.V.-R. All authors have read and agreed to the published version of the manuscript.

Funding: Research received no external funding.

Institutional Review Board Statement: Not applicable as published RCTs.

Informed Consent Statement: Published RCTs so not applicable.

Data Availability Statement: Published RCTs and PROSPERO (CRD42021250440).

Conflicts of Interest: The authors declare no conflict of interest.

\section{References}

1. Shaw, J.; Sicree, R.; Zimmet, P. Global estimates of the prevalence of diabetes for 2010 and 2030. Diabetes Res. Clin. Pr. 2010, 87, 4-14. [CrossRef] [PubMed]

2. Gubitosi-Klug, R.A. The Diabetes Control and Complications Trial/Epidemiology of Diabetes Interventions and Complications Study at 30 Years: Summary and Future Directions. Diabetes Care 2014, 37, 44-49. [CrossRef]

3. Association, A.D. 4. Foundations of care: Education, nutrition, physical activity, smoking cessation, psychosocial care, and immunization. Diabetes Care 2015, 38 (Suppl. 1), S20-S30. [CrossRef] [PubMed]

4. De Caterina, R.; Bertolotto, A.; Madonna, R.; Schmidt, E.B. $n-3$ fatty acids in the treatment of diabetic patients: Biological rationale and clinical data. Diabetes Care 2007, 30, 1012-1026. [CrossRef] [PubMed]

5. Bang, H.O.; Dyerberg, J.; Sinclair, H.M. The composition of the Eskimo food in north western Greenland. Am. J. Clin. Nutr. 1980, 33, 2657-2661. [CrossRef]

6. Crochemore, I.C.C.; Souza, A.F.; de Souza, A.C.; Rosado, E.L. $\omega-3$ Polyunsaturated Fatty Acid Supplementation Does Not Influence Body Composition, Insulin Resistance, and Lipemia in Women with Type 2 Diabetes and Obesity. Nutr. Clin. Pract. 2012, 27, 553-560. [CrossRef] [PubMed]

7. Samimi, M.; Jamilian, M.; Asemi, Z.; Esmaillzadeh, A. Effects of omega-3 fatty acid supplementation on insulin metabolism and lipid profiles in gestational diabetes: Randomized, double-blind, placebo-controlled trial. Clin. Nutr. 2015, 34, 388-393. [CrossRef] [PubMed]

8. Jo, S.; An, W.-S.; Park, Y. Erythrocyte $n$-3 Polyunsaturated Fatty Acids and the Risk of Type 2 Diabetes in Koreans: A Case-Control Study. Ann. Nutr. Metab. 2013, 63, 283-290. [CrossRef]

9. Steffen, B.T.; Steffen, L.M.; Zhou, X.; Ouyang, P.; Weir, N.L.; Tsai, M.Y. n-3 Fatty Acids Attenuate the Risk of Diabetes Associated with Elevated Serum Nonesterified Fatty Acids: The Multi-Ethnic Study of Atherosclerosis. Diabetes Care 2015, 38, 575-580. [CrossRef]

10. Browning, L.M.; Krebs, J.D.; Moore, C.S.; Mishra, G.D.; O'Connell, M.; Jebb, S.A. The impact of long chain $n-3$ polyunsaturated fatty acid supplementation on inflammation, insulin sensitivity and CVD risk in a group of overweight women with an inflammatory phenotype. Diabetes Obes. Metab. 2007, 9, 70-80. [CrossRef]

11. Giacco, R.; Cuomo, V.; Vessby, B.; Uusitupa, M.; Hermansen, K.; Meyer, B.J; Riccardi, G.; Rivellese, A.A.; KANWU Study Group. Fish oil, insulin sensitivity, insulin secretion and glucose tolerance in healthy people: Is there any effect of fish oil supplementation in relation to the type of background diet and habitual dietary intake of $n-6$ and $n-3$ fatty acids? Nutr. Metab. Cardiovasc. Dis. 2007, 17, 572-580. [CrossRef] [PubMed]

12. Jamilian, M.; Samimi, M.; Kolahdooz, F.; Khalaji, F.; Razavi, M.; Asemi, Z. Omega-3 fatty acid supplementation affects pregnancy outcomes in gestational diabetes: A randomized, double-blind, placebo-controlled trial. J. Matern. Neonatal Med. 2016, 29, 669-675. [CrossRef]

13. Pappalardo, G.; Almeida, A.; Ravasco, P. Eicosapentaenoic acid in cancer improves body composition and modulates metabolism. Nutrition 2015, 31, 549-555. [CrossRef] 
14. Hajianfar, H.; Paknahad, Z.; Bahonar, A. The Effect of Omega-3 Supplements on Antioxidant Capacity in Patients with Type 2 Diabetes. Int. J. Prev. Med. 2013, 4 (Suppl. 2), S234-S238. [PubMed]

15. Golpour, P.; Nourbakhsh, M.; Mazaherioun, M.; Janani, L.; Nourbakhsh, M.; Yaghmaei, P. Improvement of NRF2 gene expression and antioxidant status in patients with type 2 diabetes mellitus after supplementation with omega-3 polyunsaturated fatty acids: A double-blind randomised placebo-controlled clinical trial. Diabetes Res. Clin. Pr. 2020, 162, 108120. [CrossRef]

16. Dasarathy, S.; Dasarathy, J.; Khiyami, A.; Yerian, L.; Hawkins, C.; Sargent, R.; McCullough, A.J. Double-blind Randomized Placebo-controlled Clinical Trial of Omega 3 Fatty Acids for the Treatment of Diabetic Patients with Nonalcoholic Steatohepatitis. J. Clin. Gastroenterol. 2015, 49, 137-144. [CrossRef]

17. Mirhashemi, S.M.; Rahimi, F.; Soleimani, A.; Asemi, Z. Effects of Omega-3 Fatty Acid Supplementation on Inflammatory Cytokines and Advanced Glycation End Products in Patients with Diabetic Nephropathy: A Randomized Controlled Trial. Iran. J. Kidney Dis. 2016, 10, 197-204. [PubMed]

18. Orang, Z.; Mohsenpour, M.A.; Mozaffari-Khosravi, H. Effect of Omega-3 fatty acid supplementation on inflammatory markers and insulin resistance indices in patient with type 2 diabetes and nonalcoholic fatty liver: A randomized double-blind clinical trial. Obes. Med. 2020, 19, 100278. [CrossRef]

19. Raygan, F.; Taghizadeh, M.; Mirhosseini, N.; Akbari, E.; Bahmani, F.; Memarzadeh, M.R.; Sharifi, N.; Jafarnejad, S.; Banikazemi, Z.; Asemi, Z. A comparison between the effects of flaxseed oil and fish oil supplementation on cardiovascular health in type 2 diabetic patients with coronary heart disease: A randomized, double-blinded, placebo-controlled trial. Phytother. Res. 2019, 33 , 1943-1951. [CrossRef] [PubMed]

20. Zare Javid, A.; Maghsoumi-Norouzabad, L.; Ashrafzadeh, E.; Yousefimanesh, H.A.; Zakerkish, M.; Ahmadi Angali, K.; Ravanbakhsh, M.; Babaei, H. Impact of cranberry juice enriched with omega-3 fatty acids adjunct with nonsurgical periodontal treatment on metabolic control and periodontal status in type 2 patients with diabetes with periodontal disease. J. Am. Coll. Nutr. 2018, 37, 71-79. [CrossRef]

21. Soleimani, Z.; Hashemdokht, F.; Bahmani, F.; Taghizadeh, M.; Memarzadeh, M.R.; Asemi, Z. Clinical and metabolic response to flaxseed oil omega-3 fatty acids supplementation in patients with diabetic foot ulcer: A randomized, double-blind, placebocontrolled trial. J. Diabetes Its Complicat. 2017, 31, 1394-1400. [CrossRef]

22. Zheng, J.; Lin, M.; Fang, L.; Yu, Y.; Yuan, L.; Jin, Y.; Feng, J.; Wang, L.; Yang, H.; Chen, W.; et al. Effects of $n$-3 fatty acid supplements on glycemic traits in Chinese type 2 diabetic patients: A double-blind randomized controlled trial. Mol. Nutr. Food Res. 2016, 60, 2176-2184. [CrossRef] [PubMed]

23. Veleba, J.; Kopecky, J.; Janovska, P.; Kuda, O.; Horakova, O.; Malinska, H.; Kazdova, L.; Oliyarnyk, O.; Skop, V.; Trnovska, J.; et al. Combined intervention with pioglitazone and $n-3$ fatty acids in metformin-treated type 2 diabetic patients: Improvement of lipid metabolism. Nutr. Metab. 2015, 12, 52. [CrossRef] [PubMed]

24. Ansari, S.; Djalali, M.; Honarvar, N.M.; Mazaherioun, M.; Zarei, M.; Agh, F.; Gholampour, Z.; Javanbakht, M.H. The Effect of $n$-3 Polyunsaturated Fatty Acids Supplementation on Serum Irisin in Patients with Type 2 Diabetes: A Randomized, Double-Blind, Placebo-Controlled Trial. Int. J. Endocrinol. Metab. 2017, 15, e40614. [CrossRef] [PubMed]

25. Jacobo-Cejudo, M.G.; Valdés-Ramos, R.; Guadarrama-López, A.L.; Pardo-Morales, R.-V.; Martínez-Carrillo, B.E.; Harbige, L.S. Effect of $n$-3 Polyunsaturated Fatty Acid Supplementation on Metabolic and Inflammatory Biomarkers in Type 2 Diabetes Mellitus Patients. Nutrients 2017, 9, 573. [CrossRef] [PubMed]

26. Kabir, M.; Skurnik, G.; Naour, N.; Pechtner, V.; Meugnier, E.; Rome, S.; Quignard-Boulangé, A.; Vidal, H.; Slama, G.; Clément, $\mathrm{K}$. Treatment for 2 mo with $\mathrm{n}-3$ polyunsaturated fatty acids reduces adiposity and some atherogenic factors but does not improve insulin sensitivity in women with type 2 diabetes: A randomized controlled study. Am. J. Clin. Nutr. 2007, 86, 1670-1679. [CrossRef] [PubMed]

27. Atar, M.J.H.; Hajianfar, H.; Bahonar, A. The effects of omega-3 on blood pressure and the relationship between serum visfatin level and blood pressure in patients with type II diabetes. ARYA Atheroscler. 2012, 8, 27-31.

28. Moghadam, A.M.; Saedisomeolia, A.; Djalali, M.; Djazayery, A.; Pooya, S.; Sojoudi, F. Efficacy of omega-3 fatty acid supplementation on serum levels of tumour necrosis factor-alpha, C-reactive protein and interleukin-2 in type 2 diabetes mellitus patients. Singap. Med. J. 2012, 53, 615-619.

29. Hua, L.; Lei, M.; Xue, S.; Li, X.; Li, S.; Xie, Q. Effect of fish oil supplementation combined with high-intensity interval training in newly diagnosed non-obese type 2 diabetes: A randomized controlled trial. J. Clin. Biochem. Nutr. 2019, 66, 146-151. [CrossRef]

30. Chauhan, S.; Kodali, H.; Noor, J.; Ramteke, K.; Gawai, V. Role of Omega-3 Fatty Acids on Lipid Profile in Diabetic Dyslipidaemia: Single Blind, Randomised Clinical Trial. J. Clin. Diagn. Res. 2017, 11, OC13-OC16. [CrossRef]

31. Shidfar, F.; Keshavarz, A.; Hosseyni, S.; Ameri, A.; Yarahmadi, S. Effects of omega-3 fatty acid supplements on serum lipids, apolipoproteins and malondialdehyde in type 2 diabetes patients. East. Mediterr. Health J. 2008, 14, $305-313$.

32. Nahar, P.; Shah, S.; Kshirsagar, M.; Ghongane, B.; Udupa, A. A comparative study of effects of omega-3 fatty acids, alpha lipoic acid and vitamin E in type 2 diabetes mellitus. Ann. Med. Health Sci. Res. 2013, 3, 442-446. [CrossRef]

33. Liu, K.; Wang, B.; Zhou, R.; Lang, H.-D.; Ran, L.; Wang, J.; Li, L.; Kang, C.; Zhu, X.-H.; Zhang, Q.-Y.; et al. Effect of combined use of a low-carbohydrate, high-protein diet with omega-3 polyunsaturated fatty acid supplementation on glycemic control in newly diagnosed type 2 diabetes: A randomized, double-blind, parallel-controlled trial. Am. J. Clin. Nutr. 2018, 108, 256-265. [CrossRef] 
34. Mansoori, A.; Sotoudeh, G.; Djalali, M.; Eshraghian, M.R.; Keramatipour, M.; Nasli-Esfahani, E.; Shidfar, F.; Alvandi, E.; Toupchian, O.; Koohdani, F. Effect of DHA-rich fish oil on PPAR $\gamma$ target genes related to lipid metabolism in type 2 diabetes: A randomized, double-blind, placebo-controlled clinical trial. J. Clin. Lipidol. 2015, 9, 770-777. [CrossRef] [PubMed]

35. Pooya, S.; Jalali, M.D.; Jazayery, A.D.; Saedisomeolia, A.; Eshraghian, M.R.; Toorang, F. The efficacy of omega-3 fatty acid supplementation on plasma homocysteine and malondialdehyde levels of type 2 diabetic patients. Nutr. Metab. Cardiovasc. Dis. 2010, 20, 326-331. [CrossRef]

36. Fayh, A.P.T.; Borges, K.; Cunha, G.D.S.; Krause, M.; Rocha, R.; de Bittencourt, P.I.H., Jr.; Moreira, J.C.F.; Friedman, R.; Rossato, J.D.S.; Fernandes, J.R.; et al. Effects of $n-3$ fatty acids and exercise on oxidative stress parameters in type 2 diabetic: A randomized clinical trial. J. Int. Soc. Sports Nutr. 2018, 15, 18. [CrossRef] [PubMed]

37. Poursoleiman, F.; Mozaffari-Khosravi, H.; Naghdipour Biregani, A. Does omega-3 fatty acid supplementation have beneficial effects on plasma homocysteine, insulin resistance and lipid profile of type 2 diabetic patients? A randomized clinical trial. J. Nutr. Food Secur. 2018, 3, 40-50.

38. Wang, F.; Wang, Y.; Zhu, Y.; Liu, X.; Xia, H.; Yang, X.; Sun, G. Treatment for 6 months with fish oil-derived n-3 polyunsaturated fatty acids has neutral effects on glycemic control but improves dyslipidemia in type 2 diabetic patients with abdominal obesity: A randomized, double-blind, placebo-controlled trial. Eur. J. Nutr. 2017, 56, 2415-2422. [CrossRef]

39. Sarbolouki, S.; Javanbakht, M.H.; Derakhshanian, H.; Hosseinzadeh, P.; Zareei, M.; Hashemi, S.B.; Dorosty-Motlagh, A.-R.; Eshraghian, M.R.; Djalali, M. Eicosapentaenoic acid improves insulin sensitivity and blood sugar in overweight type 2 diabetes mellitus patients: A double-blind randomised clinical trial. Singap. Med. J. 2013, 54, 387-390. [CrossRef] [PubMed]

40. Woodman, R.; A Mori, T.; Burke, V.; Puddey, I.B.; Watts, G.; Beilin, L.J. Effects of purified eicosapentaenoic and docosahexaenoic acids on glycemic control, blood pressure, and serum lipids in type 2 diabetic patients with treated hypertension. Am. J. Clin. Nutr. 2002, 76, 1007-1015. [CrossRef] [PubMed]

41. Holman, R.R.; Paul, S.; Farmer, A.; Tucker, L.; Stratton, I.M.; Neil, H.A.W.; on behalf of the AFORRD study group. Atorvastatin in Factorial with Omega-3 EE90 Risk Reduction in Diabetes (AFORRD): A randomised controlled trial. Diabetologia 2009, 52, 50-59. [CrossRef] [PubMed]

42. Siniarski, A.; Haberka, M.; Mostowik, M.; Gołębiowska-Wiatrak, R.; Poręba, M.; Malinowski, K.; Gąsior, Z.; Konduracka, E.; Nessler, J.; Gajos, G. Treatment with omega-3 polyunsaturated fatty acids does not improve endothelial function in patients with type 2 diabetes and very high cardiovascular risk: A randomized, double-blind, placebo-controlled study (Omega-FMD). Atherosclerosis 2018, 271, 148-155. [CrossRef] [PubMed]

43. O'Mahoney, L.; Matu, J.; Price, O.J.; Birch, K.M.; Ajjan, R.A.; Farrar, D.; Tapp, R.; West, D.J.; Deighton, K.; Campbell, M.D. Omega-3 polyunsaturated fatty acids favourably modulate cardiometabolic biomarkers in type 2 diabetes: A meta-analysis and meta-regression of randomized controlled trials. Cardiovasc. Diabetol. 2018, 17, 1-13. [CrossRef]

44. Valdés-Ramos, R.; Guadarrama-López, A.L.; Martínez-Carrillo, B.E.; Harbige, L.S. n-3 Polyunsaturated Fatty Acids in Type 2 Diabetes Mellitus. In Bioactive Food as Dietary Interventions for Diabetes; Elsevier: Amsterdam, The Netherlands, 2019; pp. 193-209.

45. Borkman, M.; Storlien, L.H.; Pan, D.A.; Jenkins, A.; Chisholm, D.J.; Campbell, L.V. The Relation between Insulin Sensitivity and the Fatty-Acid Composition of Skeletal-Muscle Phospholipids. N. Engl. J. Med. 1993, 328, 238-244. [CrossRef]

46. Calder, P.C. Mechanisms of Action of (n-3) Fatty Acids. J. Nutr. 2012, 142, 592S-599S. [CrossRef]

47. Aas, V.; Rokling-Andersen, M.H.; Kase, E.T.; Thoresen, G.H.; Rustan, A.C. Eicosapentaenoic acid (20:5 n-3) increases fatty acid and glucose uptake in cultured human skeletal muscle cells. J. Lipid Res. 2006, 47, 366-374. [CrossRef]

48. Oh, D.Y.; Talukdar, S.; Bae, E.J.; Imamura, T.; Morinaga, H.; Fan, W.; Li, P.; Lu, W.J.; Watkins, S.M.; Olefsky, J.M. GPR120 Is an Omega-3 Fatty Acid Receptor Mediating Potent Anti-inflammatory and Insulin-Sensitizing Effects. Cell 2010, 142, 687-698. [CrossRef]

49. Kalupahana, N.S.; Claycombe, K.; Newman, S.; Stewart, T.; Siriwardhana, N.; Matthan, N.; Lichtenstein, A.H.; Moustaid-Moussa, N. Eicosapentaenoic Acid Prevents and Reverses Insulin Resistance in High-Fat Diet-Induced Obese Mice via Modulation of Adipose Tissue Inflammation. J. Nutr. 2010, 140, 1915-1922. [CrossRef]

50. Le Foll, C.; Corporeau, C.; Le Guen, V.; Gouygou, J.-P.; Bergé, J.-P.; Delarue, J. Long-chain n-3 polyunsaturated fatty acids dissociate phosphorylation of Akt from phosphatidylinositol 3'-kinase activity in rats. Am. J. Physiol. Endocrinol. Metab. 2007, 292, E1223-E1230. [CrossRef]

51. Corporeau, C.; Le Foll, C.; Taouis, M.; Gouygou, J.-P.; Bergé, J.-P.; Delarue, J. Adipose tissue compensates for defect of phosphatidylinositol 3'-kinase induced in liver and muscle by dietary fish oil in fed rats. Am. J. Physiol. Metab. 2006, 290, E78-E86. [CrossRef] [PubMed]

52. Kuda, O.; Jelenik, T.; Jilkova, Z.; Flachs, P.; Rossmeisl, M.; Hensler, M.; Kazdova, L.; Ogston, N.; Baranowski, M.; Gorski, J.; et al. $n-3$ fatty acids and rosiglitazone improve insulin sensitivity through additive stimulatory effects on muscle glycogen synthesis in mice fed a high-fat diet. Diabetologia 2009, 52, 941-951. [CrossRef] [PubMed]

53. Puhakainen, I.; Ahola, I.; Yki-Järvinen, H. Dietary supplementation with $\mathrm{n}-3$ fatty acids increases gluconeogenesis from glycerol but not hepatic glucose production in patients with non-insulin-dependent diabetes mellitus. Am. J. Clin. Nutr. 1995, 61, 121-126. [CrossRef]

54. Lapillonne, A.; Clarke, S.D.; Heird, W.C. Polyunsaturated fatty acids and gene expression. Curr. Opin. Clin. Nutr. Metab. Care. 2004, 7, 151-156. [CrossRef] [PubMed] 
55. Friedman, A.; Moe, S. Review of the Effects of Omega-3 Supplementation in Dialysis Patients. Clin. J. Am. Soc. Nephrol. 2006, 1, 182-192. [CrossRef]

56. Farmer, A.; Montori, V.; Dinneen, S.; Clar, C. Fish oil in people with type 2 diabetes mellitus. Cochrane Database Syst. Rev. 2001, 3. [CrossRef]

57. Hartweg, J.; Farmer, A.J.; Perera, R.; Holman, R.R.; Neil, H.A.W. Meta-analysis of the effects of $n-3$ polyunsaturated fatty acids on lipoproteins and other emerging lipid cardiovascular risk markers in patients with type 2 diabetes. Diabetologia 2007, 50, 1593-1602. [CrossRef]

58. Hartweg, J.; Perera, R.; Montori, V.M.; Dinneen, S.F.; Neil, A.H.; Farmer, A.J. Omega-3 polyunsaturated fatty acids (PUFA) for type 2 diabetes mellitus. Cochrane Database Syst. Rev. 2008, 1. [CrossRef] [PubMed]

59. Hartweg, J.; Farmer, A.J.; Holman, R.R.; Neil, A. Potential impact of omega-3 treatment on cardiovascular disease in type 2 diabetes. Curr. Opin. Lipidol. 2009, 20, 30-38. [CrossRef]

60. Schmidt, M.I.; Saad, M.J.; Duncan, B.B. Subclinical inflammation and obesity, diabetes and related disorders. Drug Discov. Today Dis. Mech. 2005, 2, 307-312. [CrossRef]

61. Langin, D.; Arner, P. Importance of TNF $\alpha$ and neutral lipases in human adipose tissue lipolysis. Trends Endocrinol. Metab. 2006, 17, 314-320. [CrossRef] [PubMed]

62. Tilg, H.; Moschen, A. Adipocytokines: Mediators linking adipose tissue, inflammation and immunity. Nat. Rev. Immunol. 2006, 6, 772-783. [CrossRef] [PubMed]

63. Jump, D.B. Dietary polyunsaturated fatty acids and regulation of gene transcription. Curr. Opin. Lipidol. 2002, 13, 155-164. [CrossRef] [PubMed]

64. Adkins, Y.; Kelley, D.S. Mechanisms underlying the cardioprotective effects of omega-3 polyunsaturated fatty acids. J. Nutr. Biochem. 2010, 21, 781-792. [CrossRef] [PubMed]

65. Wanten, G.J.; Calder, P.C. Immune modulation by parenteral lipid emulsions. Am. J. Clin. Nutr. 2007, 85, 1171-1184. [CrossRef] [PubMed]

66. Serhan, C.N.; Chiang, N.; Van Dyke, T.E. Resolving inflammation: Dual anti-inflammatory and pro-resolution lipid mediators. Nat. Rev. Immunol. 2008, 8, 349-361. [CrossRef]

67. Arita, M.; Bianchini, F.; Aliberti, J.; Sher, A.; Chiang, N.; Hong, S.; Yang, R.; Petasis, N.; Serhan, C.N. Stereochemical assignment, antiinflammatory properties, and receptor for the omega-3 lipid mediator resolvin E1. J. Exp. Med. 2005, 201, 713-722. [CrossRef] [PubMed]

68. Rangel-Huerta, O.D.; Aguilera, C.M.; Mesa, M.D.; Gil, A. Omega-3 long-chain polyunsaturated fatty acids supplementation on inflammatory biomakers: A systematic review of randomised clinical trials. Br. J. Nutr. 2012, 107 (Suppl. 2), S159-S170. [CrossRef] [PubMed]

69. Li, K.; Huang, T.; Zheng, J.; Wu, K.; Li, D. Effect of Marine-Derived n-3 Polyunsaturated Fatty Acids on C-Reactive Protein, Interleukin 6 and Tumor Necrosis Factor $\alpha$ : A Meta-Analysis. PLoS ONE 2014, 9, e88103. [CrossRef]

70. Buckley, J.D.; Howe, P. Anti-obesity effects of long-chain omega-3 polyunsaturated fatty acids. Obes. Rev. 2009, 10, 648-659. [CrossRef]

71. Parra, D.; Ramel, A.; Bandarra, N.; Kiely, M.; Martínez, J.A.; Thorsdottir, I. A diet rich in long chain omega-3 fatty acids modulates satiety in overweight and obese volunteers during weight loss. Appetite 2008, 51, 676-680. [CrossRef]

72. Takahashi, Y.; Ide, T. Dietary $n-3$ fatty acids affect mRNA level of brown adipose tissue uncoupling protein 1 , and white adipose tissue leptin and glucose transporter 4 in the rat. Br. J. Nutr. 2000, 84, 175-184. [CrossRef] [PubMed]

73. Pérez-Matute, P.; Pérez-Echarri, N.; Martínez, J.A.; Marti, A.; Moreno-Aliaga, M.J. Eicosapentaenoic acid actions on adiposity and insulin resistance in control and high-fat-fed rats: Role of apoptosis, adiponectin and tumour necrosis factor- $\alpha$. Br. J. Nutr. 2007, 97, 389-398. [CrossRef] [PubMed]

74. Chen, C.; Yu, X.; Shao, S. Effects of omega-3 fatty acid supplementation on glucose control and lipid levels in type 2 diabetes: A metaanalysis. PLoS ONE 2015, 10, e0139565. [CrossRef] [PubMed]

75. Brown, T.J.; Brainard, J.; Song, F.; Wang, X.; Abdelhamid, A.; Hooper, L. Omega-3, omega-6, and total dietary polyunsaturated fat for prevention and treatment of type 2 diabetes mellitus: Systematic review and meta-analysis of randomised controlled trials. BMJ 2019, 366, 14697. [CrossRef]

76. Natto, Z.S.; Yaghmoor, W.; Alshaeri, H.; Van Dyke, T.E. Omega-3 Fatty Acids Effects on Inflammatory Biomarkers and Lipid Profiles among Diabetic and Cardiovascular Disease Patients: A Systematic Review and Meta-Analysis. Sci. Rep. $2019,9,18867$. [CrossRef]

77. Gao, C.; Liu, Y.; Gan, Y.; Bao, W.; Peng, X.; Xing, Q.; Gao, H.; Lai, J.; Liu, L.; Wang, Z.; et al. Effects of fish oil supplementation on glucose control and lipid levels among patients with type 2 diabetes mellitus: A Meta-analysis of randomized controlled trials. Lipids Health Dis. 2020, 19, 1-10. [CrossRef] [PubMed]

78. Caughey, G.; Mantzioris, E.; Gibson, R.; Cleland, L.G.; James, M.J. The effect on human tumor necrosis factor alpha and interleukin 1 beta production of diets enriched in $n-3$ fatty acids from vegetable oil or fish oil. Am. J. Clin. Nutr. 1996, 63, 116-122. [CrossRef] [PubMed]

79. Forouhi, N.G.; Imamura, F.; Sharp, S.J.; Koulman, A.; Schulze, M.B.; Zheng, J.; Ye, Z.; Sluijs, I.; Guevara, M.; Huerta, J.M.; et al. Association of plasma phospholipid $n-3$ and $n-6$ polyunsaturated fatty acids with type 2 diabetes: The EPIC-InterAct case-cohort study. PLoS Med. 2016, 13, e1002094. [CrossRef] 
80. ERA-JUMP Study Group; Choo, J.; Ueshima, H.; Curb, J.D.; Shin, C.; Evans, R.W.; El-Saed, A.; Kadowaki, T.; Okamura, T.; Nakata, K.; et al. Serum $\mathrm{n}-6$ fatty acids and lipoprotein subclasses in middle-aged men: The population-based cross-sectional ERA-JUMP Study. Am. J. Clin. Nutr. 2010, 91, 1195-1203. [CrossRef] [PubMed]

81. Wu, J.H.Y.; Marklund, M.; Imamura, F.; Tintle, N.; Korat, A.V.A.; de Goede, J.; Zhou, X.; Yang, W.-S.; Otto, M.C.D.O.; Kröger, J.; et al. Omega-6 fatty acid biomarkers and incident type 2 diabetes: Pooled analysis of individual-level data for 39740 adults from 20 prospective cohort studies. Lancet Diabetes Endocrinol. 2017, 5, 965-974. [CrossRef]

82. Harbige, L.S. Fatty acids, the immune response, and autoimmunity: A question of $n-6$ essentiality and the balance between $n-6$ and $n$-3. Lipids 2003, 38, 323-341. [CrossRef] [PubMed]

83. Khalili, L.; Alipour, B.; Jafarabadi, M.A.; Hassanalilou, T.; Abbasi, M.M.; Faraji, I. Probiotic assisted weight management as a main factor for glycemic control in patients with type 2 diabetes: A randomized controlled trial. Diabetol. Metab. Syndr. 2019, 11, 5. [CrossRef] [PubMed] 